\title{
A longitudinal study of the effects of internet use on subjective well-being
}

Dario Paez, Gisela Delfino, Salvador Vargas-Salfate, James H. Liu, Homero Gil De Zúñiga, Sammyh Khan \& Maite Garaigordobil

To cite this article: Dario Paez, Gisela Delfino, Salvador Vargas-Salfate, James H. Liu, Homero Gil De Zúñiga, Sammyh Khan \& Maite Garaigordobil (2019): A longitudinal study of the effects of internet use on subjective well-being, Media Psychology, DOI: 10.1080/15213269.2019.1624177

To link to this article: https://doi.org/10.1080/15213269.2019.1624177

\section{9.}

Submit your article to this journal

Џلll Article views: 135

Q View related articles $\square$

View Crossmark data ¿ 


\title{
A longitudinal study of the effects of internet use on subjective well-being
}

\author{
Dario Paez $\mathbb{( 1}^{\mathrm{a}, \mathrm{b}}$, Gisela Delfino $\mathbb{1}^{\mathrm{c}}$, Salvador Vargas-Salfate $\mathbb{1}^{\mathrm{b}}$, James H. Liu (1) ${ }^{\mathrm{d}}$, \\ Homero Gil De Zúñiga (10) ${ }^{\text {eff }}$, Sammyh Khan $\mathbb{1}^{\mathrm{g}}$, and Maite Garaigordobil (10)
}

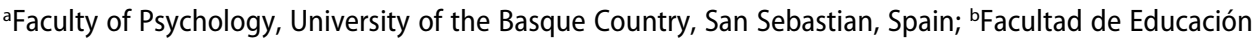
y Ciencias Sociales, Universidad Andres Bello, Santiago de Chile, Chile; 'Faculty of Psychology and Psychopedagogy, Pontifical Catholic University of Argentina, National Scientific and Technical Research Council, Buenos Aires, Argentina; 'School of Psychology, Massey University, Auckland, New Zealand; ${ }^{e}$ College of Social Sciences, University of Vienna, Vienna, Austria; ${ }^{\mathrm{f}}$ Facultad de Comunicación y Letras, Universidad Diego Portales, Santiago de Chile, Chile; ${ }^{9}$ School of Psychology, Keele University,

Newcastle-under-Lyme, UK
\end{abstract}

\begin{abstract}
This study examined how internet use is related to subjective well-being, using longitudinal data from 19 nations with representative online samples stratified for age, gender, and region ( $N=7122,51.43 \%$ women, $\left.M_{\text {age }}=45.26\right)$. Life satisfaction and anxiety served as indices of subjective well-being at time 1 ( $\mathrm{t} 1)$ and then six months later (t2). Frequency of internet use (hours online per day) at $\mathrm{t} 1$ correlated with lower life satisfaction, $r=-.06$, and more anxiety, $r=.13$ at t2. However, after imposing multivariate controls, frequency of internet use (t1) was no longer associated with lower subjective well-being ( $\mathrm{t} 2$ ). Frequency of social contact by internet and use of internet for following rumors ( $t 1)$ predicted higher anxiety (t2). Higher levels of direct (faceto-face plus phone) social contact (t1) predicted greater life satisfaction (t2). In multivariate analyses, all effect sizes were small. Society-level individualism-collectivism or indulgencerestraint did not show a direct effect on outcomes nor moderate individual-level associations. Results are discussed in the framework of the internet as a displacement of social contact versus a replacement of deficits in direct contact; and as a source of positive and negative information.
\end{abstract}

In the last two decades, an increasing number of studies have analyzed the relationship between internet use and subjective well-being. While McKenna and Bargh's (1999) review concluded that social interaction through the internet has "surprisingly strong effects on people's real life" (p.1), other reviews have yielded complex, and at times contradictory results. In this paper, we first summarize some of the main findings in this literature and then review different explanations provided for the negative and positive effects of internet use. We also discuss how culture could modulate these

CONTACT Gisela Delfino gisela_delfino@uca.edu.ar

This article has been republished with minor changes. These changes do not impact the academic content of the article.

(c) 2019 Taylor \& Francis Group, LLC 
effects. It is important to note that debate about positive and negative effects of internet use is very much open, because most previous research relies on cross-sectional studies, many employ university students, and results are concentrated on a few countries (Castellacci \& Tveito, 2018). We contribute to this literature by analyzing the relationship between internet use and subjective well-being in a longitudinal study of anxiety and life satisfaction among nationally representative samples in 19 nations.

A systematic review of meta-analyses shows a small negative association between internet use and well-being. A meta-analysis by Huang (2010) was based on 40 studies $(N=21,258)$ : it examined the relationship between internet use and well-being, including measures of self-esteem and life satisfaction, and found a small negative association $(k=43, r=-.039)$, where the type of measurement did not moderate correlation size. A second meta-analysis (Song et al., 2014) based on 18 studies $(N=8,798)$ examined the relationship between Facebook use and loneliness and found a small positive correlation $(k=18, r=.166)$. A third meta-analysis (Çikrıkci, 2016) based on 23 studies $(N=21,054)$ found that frequency of internet use had a significant negative correlation with well-being (as indexed by satisfaction with life, self-esteem, and subjective well-being) (overall $k=28, r=-.18$ ). We carried out an integration of these meta-analyses and results showed a weighted $r=-.11$ between internet use and subjective well-being, as indexed by lower life satisfaction and self-esteem. Internet use also had small associations with low positive affect, depressive symptoms, high negative affect, and anxiety.

Given that this relatively small effect size is mainly based on cross-sectional correlations, we will attempt to show a more complex view of both positive and negative influences of internet use on subjective well-being. For instance, Prizant-Passal, Shechner, and Aderka's (2016) meta-analysis found that total time spent online, email use, and instant messaging use did not correlate with social anxiety, but time spent on gaming, and problematic or excessive internet use were associated with anxiety. While excessive use and gaming provoke negative outcomes, other aspects of internet use could have neutral or even positive effects. Garcia Mazzieri (2014, November) found that internet use for study purposes was positively related to subjective well-being, while the opposite was found for internet use for gaming and leisure. Therefore, our study examines not only the amount of time on the internet, but also differentiates between types of use: internet use for social contact could have positive effects, while internet use involving stress-related processes (e.g., being bullied) could provoke negative outcomes and anxiety. To have a subtler and more complex view of the influence of internet use, it is necessary to have longitudinal data so as to test the temporal precedence of the supposed cause, as well as to take into account the baselines of the predicted criterion variable. This study will analyze 
the influence of internet use at one temporal point and the predictive value of this variable in changes of the criterion variables six months later.

\section{Approaches to the relationship between internet use and subjective well-being}

The use of the internet could be conceived as part of a set of diverse contributory antecedents and functions related to well-being. A first approach to this relationship simply proposes that the excessive use of internet is detrimental for mental health (Prizant-Passal et al., 2016). The few available longitudinal analyses show that greater internet use (e.g., internet hours, instant messenger use) tends to be related to higher levels of depression, loneliness and stress over time, and a decrease in happiness (Kraut et al., 1998; Van Den Eijnden, Meerkerk, Vermulst, Spijkerman, \& Engels, 2008). At the opposite end, overall individuals' happiness predicted a decrease of compulsive internet use over time (Muuse, Finkenauer, Kerkhorf, \& Billedo, 2014).

However, it is difficult to establish what amount of time online is too much (Orban, 2018). Negative experience on social media (e.g., being bullied or becoming worried about physical appearance) disproportionately affect children and young people. In contrast, according to Przybylski and Weinstein (2017) moderate use of digital technology is not intrinsically harmful, and may be advantageous. These authors conceive of a curvilinear relationship: medium level use of internet is associated with better well-being, while low and high levels are related to worse well-being - these extreme levels suggest isolation at the one end, versus excessive absorption in virtual communication at the other end.

A complementary approach (Huang, 2010; Kraut et al., 1998) states a displacement hypothesis where intensive internet use for communication displaces face-to-face interaction and provokes negative outcomes, because it enhances social isolation, and decreases opportunities for social support and integration. This deficit provokes a decrease in positive affect, self-efficacy, and self-esteem. Kraut et al.'s (1998) study was one of the first to highlight that increased time spent online could be related to a decline in communication with relatives, as well as a reduction in social integration, leading to increased feelings of depression and loneliness. Further, Reinecke et al.'s (2017) study showed internet use to be positively related to perceived stress and had significant indirect effects on depression and anxiety. Other studies have found a positive association between internet use, increase in social anxiety and a decreased sense of belonging to offline social networks (Song et al., 2014). Kim, LaRose, and Peng (2009) showed that high levels of loneliness and low social skills were associated with compulsive internet use. Intensive internet use was also associated with a high level of negative life events. These increased stress levels probably isolate individuals from positive social activities and lead them into more loneliness. Summarizing, 
the main idea behind the displacement hypothesis is that extensive internet use outside of face-to-face networks might weaken or "displace" existing family and friend interactions, and therefore increase feelings of loneliness and depression (Pantic, 2014). This model presupposes a negative association between social contact by internet and direct social contact. It also expects that frequent internet use should predict a decrease in well-being. However, most data in support of this hypothesis are correlational (but see Shklovski, Kraut, \& Rainie, 2004, for longitudinal data supporting the displacement hypothesis).

An alternative is the replacement hypothesis: for people with limited social skills in face-to-face interaction and/or living in a socially limited environment (e.g., migrants living abroad or people distant from relatives and friends), internet use can replace face-to-face social support and facilitate well-being. This idea is partially supported by accumulated longitudinal findings showing that loneliness increases internet use, rather than internet use leading to loneliness (Gosling \& Mason, 2015; Song et al., 2014). Davis (2001) suggested in a similar way that people with deficits in social skills (e.g., lonely and depressed individuals) turn to online communication because it is relatively less risky and easier than face-to-face communication due to its greater anonymity (Caplan, 2005). Some studies report evidence that internet use beneficially affects users. For example, online networking may help mitigate a decline in face-to-face social participation by enabling users to socially interact with others in cyberspace (Antoci, Sabatini, \& Sodini, 2012). In this case, internet use could be adaptive, because engaging in online social network activities "replaces" the lack of a face-to-face social network. This approach states a direct and independent positive effect of internet use for social contact on well-being.

Another approach proposes an augmentation hypothesis, reasoning that internet use for communication complements existing social interaction and amplifies their effects, both in terms of positive and negative outcomes (Huang, 2012). For example, Kraut et al. (2002) suggested that positive augmentation could take place through internet-based social support: among people with high levels of social support, internet use is synergic and increases well-being (Dienlin, Masur, \& Trepte, 2017; Lee, 2009; Trepte, Dienlin, \& Reinecke, 2015). In this case "the rich get richer": among well-adjusted people, internet use enhances social integration and well-being. Social integration and contact with others impact positively on well-being, and this provides more social support in times of crisis (Maybery, Jones-Ellis, Neale, \& Arentz, 2006). Moreover, because the social sharing (mediated by the internet in this case) of positive experience and emotions enhances positive affect and social connections (the so-called capitalization effect, see Reis et al., 2010), internet use is conceived as a technological tool reinforcing subjective well-being. When the internet is used to give and receive support, particularly by increasing social contact among close relations, it enhances well-being (Pantic, 2014). In addition, 
internet use could complement face-to-face social support as a form of adaptive coping through information search. Cross-sectional results support positive augmentation by showing that internet communication with a particular person tends to be strongly associated with phone and face-to-face communication with that person. However, longitudinal analyses of the same data evidenced greater internet use during a period of time were associated with declines in personal visits (Shklovski et al., 2004). This result shows the limits of cross-sectional analyses and this is why we want to test the hypothesis with longitudinal data.

On the other hand, negative augmentation could also be the consequence of internet use where stressful content and processes decrease well-being. The "poor get poorer", for example, when the use of the internet to follow rumors causes uncertainty, increases anxiety and negative affect (Gosling \& Mason, 2015). Cyberbullying or being the low status target of repeated intentionally aggressive communications by a high status perpetrator in an electronic context has a similar outcome (i.e., negative augmentation) to face-to-face bullying, including anxiety, depression and low self-esteem (see Garaigordobil, 2011; Kowalski, Giumetti, Schoreder, \& Lattanner, 2014; Pantic, 2014).

Table 1 summarizes the main arguments in the literature.

\section{Goals and hypotheses}

In summary, the aim of this paper is to analyze the effect of internet use on subjective well-being, considering the impact of different forms of internet use. This study focuses on the longitudinal effect of different types of internet use on well-being, as measured by life satisfaction and anxiety (Russell \& Carroll, 1999). Previous longitudinal studies have examined the association between internet use and anxiety, social anxiety, depression, distress, satisfaction with life and selfesteem. However, these symptoms and overall well-being have been examined mainly as predictors, and less as outcomes. Additionally, studies have used relatively small samples limited to a few nations (but see Anderson, Steen, \& Stavropoulo, 2017, for a review of longitudinal studies with Asian adolescents, Muuse et al., 2014, for a longitudinal study with German adults). Our study focuses on symptoms and well-being as consequences of internet use in large samples of adults in 19 nations. Hypotheses are as follows:

H1: Negative effect of use of the internet: the number of hours on the internet per day at time 1 predicts lower subjective well-being at time 2 .

H2: Displacement hypothesis: higher internet use at time 1 displaces direct social contact, and therefore higher internet use (and lower direct social contact) at time 1 predicts an increase of anxiety symptoms and a decrease of life satisfaction (i.e. lower subjective well-being) at time 2. 


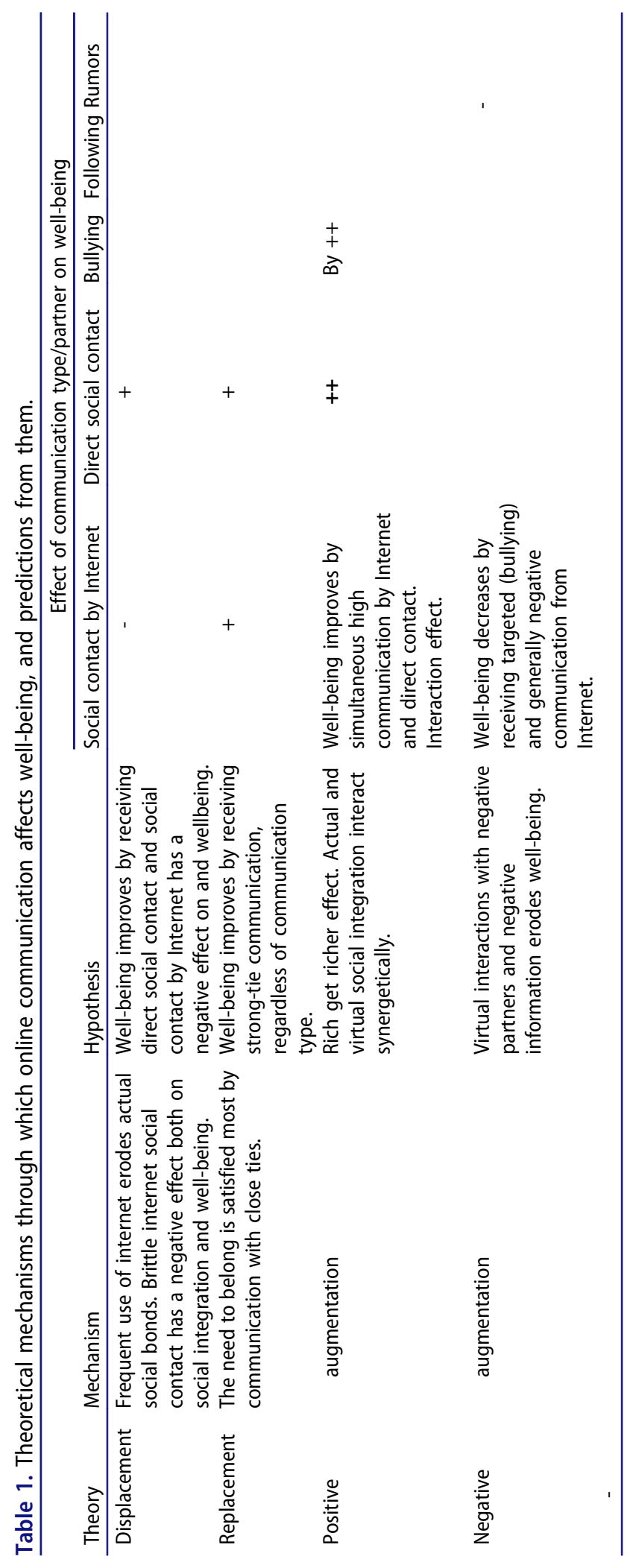


H3: Replacement hypothesis: high internet use replaces face-to-face deficits in social support and therefore high internet use for social contact at time 1 is positively related to subjective well-being at time 2 .

H4: Positive augmentation hypothesis: direct social contact and internet use for social interaction at time 1 are positively related, and both positively predict well-being at time 2 .

H5: Negative augmentation hypothesis: searching for rumors and being electronically exposed to bullying at time 1 are negatively correlated to wellbeing at time 2 .

Finally, we argue that the relation between internet use and well-being differs in both aspects: cognitive and affective subjective well-being. Subjective well-being involves an emotional aspect of positive and negative affect, and a cognitive or evaluative aspect of global and domain-specific life satisfaction (Arthaud-Day, Rode, Mooney, \& Near, 2005; Dodge, Daly, Huyton, \& Sanders, 2012; Ryan \& Deci, 2001). Cognitive and positive affect aspects of subjective well-being are more stable and more strongly related to social contact and positive events than negative affective aspects (Helliwell, Layard, \& Sachs, 2017). In reference to affective well-being, negative affect is related to neuroticism, self-reported stress, health complaints, and the frequency of unpleasant events. Positive affect has been found to correlate with extraversion, sociability, and the frequency of pleasant events (Maybery et al., 2006). Thus, this study examines whether cognitive aspects of subjective well-being (such as life satisfaction) and negative affective components (like anxiety) will have different associations with internet use. As a consequence, the sixth hypothesis of this study formulates that:

H6: Negative information coming from the internet (rumors, being bullied) (t1) is positively correlated to negative affect (i.e. anxiety t2), while positive social contact (face-to-face and by internet), correlates to higher life satisfaction (t2).

The study aims at comparing and contrasting the same hypotheses across different sociocultural contexts to provide much-needed replication in the literature. Furthermore, we also seek to examine potential cross-cultural differences. Due to this study being focused on the effects of internet use, sociability and well-being, an important cultural dimension is Individualism-Collectivism (Hofstede, 2001). Collective level cross-sectional analysis shows that cultural individualism, controlling for GDP and Human Index of Development, is associated with higher well-being. At the society level, Hofstede's individualism is related to Schwartz's Affective Autonomy values, including items like pleasure, 
life enjoyment, etc. (Basabe \& Ros, 2005; Hofstede, 2001). Values of stimulation and hedonism embedded in this type of culture enhance subjective well-being (Basabe et al., 2002; Basabe \& Ros, 2005). Hedonism is potentially associated with hedonic well-being or with a positive affect balance, because of its emphasis on pleasant stimuli. Hence, the study samples 19 nations from the Americas, Western and Eastern Europe, and Asia.

H7: National scores of cultural individualism are positively associated with subjective well-being.

This cultural dimension is also related to different types of sociability. Triandis (2001), based on limited evidence, proposed that collectivism is related to a need of affiliation. However, in fact, people in collectivist cultures have fewer and more stable social contacts and show less need for affiliation (Hofstede, 2001). In collectivistic countries, people belong to fewer groups and have stronger traditional social bonds, and thus have less need to be affiliative. Personal relationships like friendships can be predetermined by family or neighborhood bonds.

People in individualistic cultures, on the other hand, tend to have varied and voluntary social contacts and depend more on these for their well-being. For instance, the association between satisfaction with friends and life satisfaction is higher in individualistic nations (Diener \& Diener, 2009). Empirical evidence suggests that need for affiliation scores are correlated with Individualism, $r_{s}(23)$ $=.43, p<.005$ (Hofstede, 2001, p. 225). In individualistic societies, personal and affective relationships are more likely to be acquired by each individual personally. In this way, need for affiliation and constructing friendship, group belonging and so on, becomes more an issue (Hofstede, 2001). Due to individualism being associated with a greater need for affiliation, the factors that help or hinder this need, and influence social support, should impact more strongly on wellbeing. In collectivist cultures, where social support is more predetermined by people belonging to fewer groups, the effects of the internet on social relationships should be weaker. For this reason, we assume that greater internet use and the potential resulting deficit of direct social contacts (and their negative impact on well-being) will affect more people living in individualistic cultures.

H8: There is a cross-level moderation effect: the negative association between excessive internet use and well-being, as well as the positive association between social interaction by internet and well-being, is stronger in more individualistic nations.

Indulgence-Restraint is another cultural dimension that could be relevant for the effects of social contact and internet use. Following Hofstede (2011), the Indulgence pole stands for a society (e.g., Colombia) that allows relatively free 
gratification of drives related to enjoying life. Restraint stands for a society (e.g., Egypt) that suppresses gratification of needs and regulates it by means of strict social norms. Due to indulgent cultures giving more importance to factors like freedom of speech, personal control, and expression, this is likely to have an impact on how willing people living in this culture are to communicate, including by internet.

H9: The positive association between social interaction through the internet and well-being is stronger in more indulgent nations, as well as the association between frequency of internet use and well-being.

\section{Methods}

\section{Participants}

We employed an online panel where participants were collected by international polling firm Nielsen, employing stratified samples on age, gender, and region, based on census information for each country (for details see Gil de Zúñiga, Ardèvol-Abreu, Diehl, Patiño, \& Liu, 2019; Gil de Zúñiga \& Liu, 2017). The sample for time 1 was collected during September 2015 in 19 countries and during March 2016 for the follow-up with the same people in time 2. Individuals from the following countries/societies participated: Argentina, Brazil, China, Estonia, Germany, Indonesia, Italy, Japan, New Zealand, Philippines, Poland, Russia, South Korea, Spain, Taiwan, Turkey, Ukraine, United Kingdom, and the United States. For this study, cases from the countries with both samples (time 1 and time 2) and valid answers in all the variables in the analyses are used. This procedure retained 7,122 participants $\left(51.43 \%\right.$ women; $\left.M_{\text {age }}=45.26, S D=14.501\right)$ with sample sizes ranging from 80 (Ukraine) to 604 (Estonia).

\section{Instruments}

We measured subjective well-being (life satisfaction and anxiety) in both waves. The other variables were measured only in wave 1 .

\section{Life satisfaction}

We selected five items from the Personal Well-being Index (PWI; Lau, Cummins, \& Mcpherson, 2005) to measure life satisfaction as a whole, for health, standard of living, safety and security, and relationships. Answers ranged from 1 (completely dissatisfied) to 7 (completely satisfied). The scale had satisfactory reliability in both waves $\left(\alpha_{\mathrm{w} 1}=.87\right.$ and $\left.\alpha_{\mathrm{w} 2}=.87\right)$ and they were significantly related to each other $(r=.77, p<.001)$, (confirmatory factor analyses: wave $1, \chi^{2}$ 
$(5)=477.384, p<.001, \mathrm{CFI}=.973, \mathrm{TLI}=.945, \mathrm{RMSEA}=.115$, and wave $2, \chi^{2}(5)$ $=293.794, p<.001, \mathrm{CFI}=.984, \mathrm{TLI}=.967, \mathrm{RMSEA}=.090)^{1,2}$.

\section{Anxiety}

We used the Generalized Anxiety Disorder scale (GAD-7; Spitzer, Kroenke, Williams, \& Löwe, 2006), asking participants to rate the frequency by which they have felt bothered by (a) feeling nervous, anxious, or on edge, (b) not being able to stop or control worrying, (c) worrying too much about different things, (d) having trouble relaxing, (e) being so restless that it's hard to sit still, ( $f$ ) becoming easily annoyed or irritable, and (g) feeling afraid as if something awful might happen. Answers ranged from 1 (never) to 7 (always), with alpha coefficients suggesting the scale was highly reliable in both waves $\left(_{\mathrm{w} 1} \alpha=.94\right.$ and $\mathrm{w}_{2} \alpha=.94$ as well) and that they were significantly related to each other (Spearman-Brown coefficient $=.70$ ). These items are conceived of as measuring high negative affect (confirmatory factor analyses: wave $1, \chi^{2}$ $(14)=1407.878, p<.001, \mathrm{CFI}=.965, \mathrm{TLI}=.947, \mathrm{RMSEA}=.118$, and wave 2 , $\chi^{2}(14)=1320.174, p<.001$, CFI $=.970$, TLI $=.954$, RMSEA $\left.=.115\right)$.

The following variables were measured at time 1 only:

\section{Amount of time connected to internet per day}

We asked participants to say how many hours they tended to be connected online during a normal day (on a 0 to 24 -h scale).

\section{Social interaction by internet}

We used five items to assess the frequency participants used the internet to stay in touch with family and friends by (a) instant messaging, (b) email, (c) social media, and used social media to (d) meet people who share their interests, (e) contact people they would not meet otherwise. Answer options ranged from 1 (never) to 7 (always). The scale had acceptable reliability in our sample $\left(\alpha_{\mathrm{w} 1}=.79\right.$, confirmatory factor analysis: $\chi^{2}(5)=866.734, p<$ $.001, \mathrm{CFI}=.926, \mathrm{TLI}=.852$, RMSEA $=.156)$.

\section{Being cyberbullied or harassed online}

We asked participants how frequently they experienced cyberbullying or have been harassed online. Answer options ranged from 1 (never) to 7 (always).

\section{Pay attention to rumors}

We asked participants how frequently they paid attention to rumors when online. Answer options ranged from 1 (never) to 7 (always).

\section{Direct social interaction}

We asked participants how often "they keep in touch with family and friends" by (a) meeting face to face or (b) talking on the phone. Answer 
options ranged from 1 (never) to 7 (always). Both items were highly correlated $(r=.567, p<.001)$.

\section{Collective level variables}

We used individualism and indulgence scores provided by Hofstede (2015) as country/society-level variables. For individualism, the scores in our database ranged from 14 (Indonesia) to 91 (United States), while for indulgence varied from 16 (Estonia) to 75 (New Zealand). Individualism is strongly related to high GDP and Human Development Index, and due to the limited number of nations in our study, these socioeconomic contextual variables were not included. $^{3}$

Individual-level control variables: age and gender $(0=$ male, $1=$ female $)$.

\section{Results}

\section{Preliminary analyses}

In order to analyze possible attrition bias, we compared cases included in the analyses with those excluded, considering satisfaction with life and anxiety in the first wave. We found non-significant differences regarding satisfaction with life, $t(20,686)=.648, p=.517$, but significant differences in anxiety, $t(20,351)=9.705, p<.001, d=.200 .^{4}$ Individuals included in the analyses, which correspond to those that participated in both waves, reported slightly milder levels of anxiety $(M=3.15, S D=1.378)$, as compared to those excluded $(M=3.43, S D=1.384)$, who only participated in wave 1 .

\section{Descriptive and correlation analyses}

Descriptive statistics for the dependent variables are presented in Table 2. Regarding life satisfaction, considering effect size, the mean in the first wave kept stable six months after, $t(7121)=3.81, p<.001, d=.030$. By country, there were almost no differences in this scale, $F(18,7103)=42.52, p<.001$, with a small effect size, $\eta^{2}=.097$. For the anxiety measure, the overall mean in the first wave was not significantly different from the overall score in the second wave, $t(7121)=1.56, p=.118$. In addition, there were small differences between countries, $F(18,7103)=24.19, p<.001, \eta^{2}=.058$.

The descriptive statistics for the independent variables (at time 1) are presented in Table 3. For the first predictor variable, amount of time connected to internet per day, we found small differences by country, $F$ (18, $7103)=36.55, p<.001, \eta^{2}=.085$. Concerning social interaction by internet, there were differences by country, $F(18,7103)=91.76, p<.001$, with a medium effect size, $\eta^{2}=.189$. The highest scores were observed in Indonesia, and the lowest scores in Japan. Regarding direct social interaction, 
Table 2. Descriptive statistics (Dependent variables).

\begin{tabular}{|c|c|c|c|c|c|c|c|c|c|}
\hline & \multicolumn{2}{|c|}{$\begin{array}{l}\text { Satisfaction with Life } \\
\text { (t1) }\end{array}$} & \multicolumn{2}{|c|}{$\begin{array}{l}\text { Satisfaction with Life } \\
\text { (t2) }\end{array}$} & \multicolumn{2}{|c|}{$\begin{array}{l}\text { Anxiety } \\
\text { (t1) }\end{array}$} & \multicolumn{2}{|c|}{ Anxiety (t2) } & \multirow[b]{2}{*}{ Sample size } \\
\hline & $M$ & $S D$ & $M$ & $S D$ & $M$ & $S D$ & $M$ & $S D$ & \\
\hline Argentina & 5.18 & 0.99 & 5.17 & 0.98 & 3.24 & 1.49 & 3.20 & 1.41 & 285 \\
\hline Brazil & 4.96 & 1.04 & 5.00 & 1.05 & 3.88 & 1.32 & 3.99 & 1.42 & 265 \\
\hline China & 4.93 & 0.97 & 4.91 & 1.01 & 3.19 & 1.08 & 3.05 & 1.22 & 328 \\
\hline Estonia & 4.88 & 0.97 & 4.90 & 0.98 & 2.86 & 1.23 & 2.71 & 1.16 & 604 \\
\hline Germany & 5.11 & 1.15 & 5.11 & 1.10 & 3.14 & 1.42 & 3.11 & 1.41 & 511 \\
\hline Indonesia & 5.26 & 1.12 & 5.27 & 1.12 & 3.22 & 1.31 & 3.35 & 1.33 & 252 \\
\hline Italy & 4.88 & 1.12 & 4.81 & 1.14 & 3.61 & 1.25 & 3.60 & 1.31 & 487 \\
\hline Japan & 4.08 & 1.17 & 4.09 & 1.17 & 2.81 & 1.41 & 2.74 & 1.38 & 464 \\
\hline South Korea & 4.09 & 1.09 & 4.10 & 1.06 & 3.07 & 1.31 & 3.06 & 1.35 & 453 \\
\hline New Zealand & 5.16 & 1.12 & 5.11 & 1.09 & 2.86 & 1.27 & 2.89 & 1.29 & 519 \\
\hline Philippines & 5.06 & 1.04 & 5.14 & 1.24 & 2.84 & 1.25 & 2.92 & 1.31 & 121 \\
\hline Poland & 4.76 & 1.09 & 4.71 & 1.07 & 3.36 & 1.45 & 3.30 & 1.43 & 487 \\
\hline Russia & 4.69 & 1.00 & 4.58 & 1.06 & 3.14 & 1.37 & 3.23 & 1.36 & 422 \\
\hline Spain & 5.08 & 1.11 & 5.10 & 1.13 & 3.30 & 1.47 & 3.32 & 1.52 & 237 \\
\hline Taiwan & 4.58 & 1.05 & 4.44 & 1.02 & 3.38 & 1.09 & 3.32 & 1.13 & 362 \\
\hline Turkey & 4.65 & 1.24 & 4.47 & 1.29 & 3.59 & 1.37 & 3.72 & 1.44 & 263 \\
\hline United Kingdom & 5.02 & 1.13 & 4.98 & 1.15 & 3.04 & 1.58 & 2.95 & 1.55 & 574 \\
\hline Ukraine & 4.31 & 1.07 & 4.25 & 1.20 & 3.25 & 1.19 & 3.33 & 1.25 & 80 \\
\hline USA & 5.24 & 1.10 & 5.20 & 1.04 & 2.61 & 1.38 & 2.60 & 1.39 & 408 \\
\hline Total & 4.84 & 1.14 & 4.80 & 1.15 & 3.15 & 1.38 & 3.13 & 1.39 & 7122 \\
\hline
\end{tabular}

there were also small differences by country, $F(18,7103)=37.15, p<.001, \eta^{2}$ $=.086$. The variable pay attention to rumors presented differences by country, $F(18,7103)=84.10, p<.001$, with a medium effect size, $\eta^{2}=.176$. The highest average was observed in Indonesia, and the lowest mean in the USA. In being cyberbullied or harassed online, we found little differences by country, $F(18,7103)=28.61, p<.001, \eta^{2}=.068$, with China presenting the highest scores, and Estonia and New Zealand with the lowest scores. The matrix of correlations between all variables is presented in Table 4.

\section{Multiple linear regressions}

We conducted multiple linear regressions to test hypotheses after taking into account the inter-correlations between predictors and after including baseline measures as controls. A series of multi-level linear regression models were carried out, because our data have a hierarchical society-based structure (i.e., with individuals nested within societies). ${ }^{5}$ Linear regression models, using an OLS estimator, need independent residual terms; this is violated when the data are hierarchically structured. By randomizing the intercept (i.e., allowing it to vary by country), multilevel linear regressions overcome this issue (Gelman \& Hill, 2007). We employed the restricted maximum likelihood estimator, because it is the most appropriate estimator when level-two units (societies) are few. ${ }^{6}$ In the first model, we only included the intercept, so that we could estimate the intra-class correlation and establish a baseline model to compare 


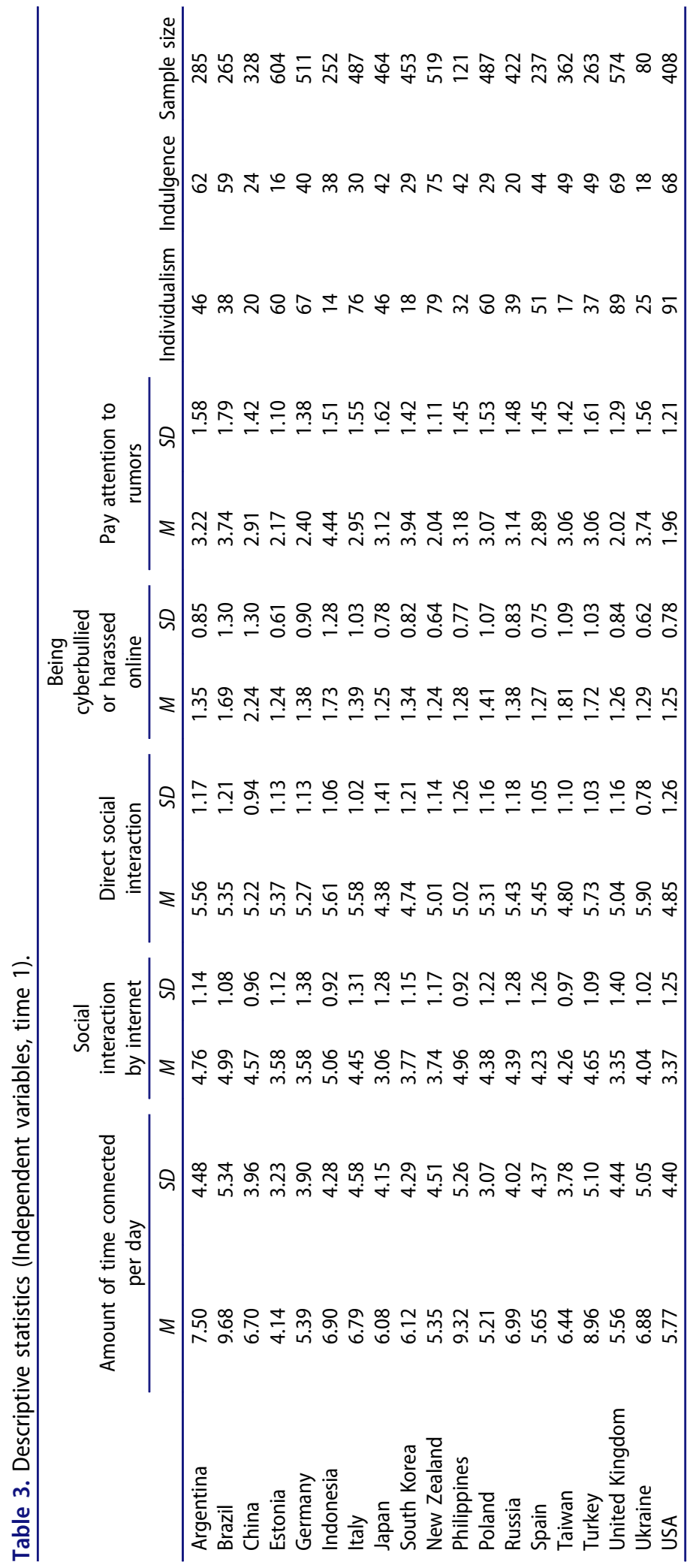




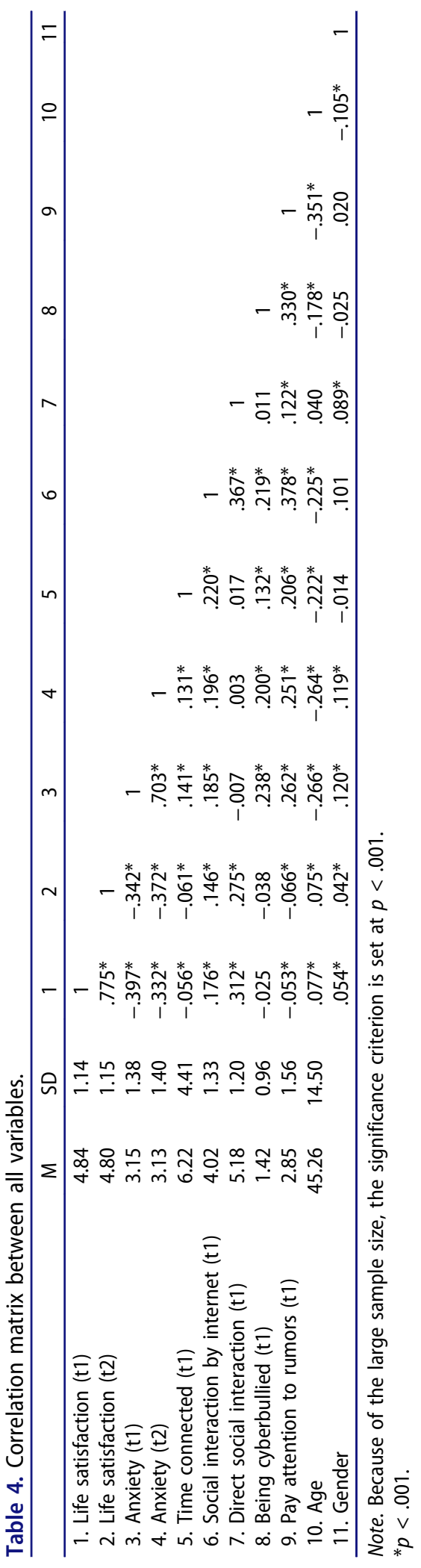


with subsequent models. Next, we included the individual-level independent variables, country-mean centering all continuous predictors. The interaction term between direct social interaction and social interaction by internet examined specifically the augmentation hypothesis. Then, in the third model we included individualism as a country/society-level predictor, which was grand mean centered, and also two interaction terms: one examined the moderation effect of the Level 2 variable (individualism) on the association of internet use (time) with well-being (life satisfaction and anxiety), the other inspected this association mediated by internet social interaction and well-being. A quadratic term examined the non-linear association between internet use and well-being. Finally, we performed the same analyses, but instead of individualism, we used indulgence as the society-level predictor. ${ }^{7}$ In all models, we set the significance criterion at $p<.001$, because of the large sample size.

The models related to life satisfaction ( $\mathrm{t} 2$ ) are presented in Table 5. In the first model, we obtained an intraclass correlation of .10. In other words, $10 \%$ of the dependent variable's variance was explained by the hierarchical structure of data. This amount is high enough to justify the use of multi-level models - some authors propose a cut off .05 (LeBreton \& Senter, 2008) but others argue that the decision should not be based on a statistical cut-off point, but merely on the structure of data collection and theory (Nezlek, 2008). The inclusion of the independent variables improved model fit $(\Delta-2 \log =-3001.33, \Delta \mathrm{AIC}=-5984.66, \Delta \mathrm{BIC}=-5922.82)$, explaining $57 \%$ of the individual-level variance. After controlling for baseline life satisfaction ( $\mathrm{t} 1$ ), the outcome variable (life satisfaction at $\mathrm{t} 2$ ) was positively predicted only by direct social interaction ( $\mathrm{t} 1$ ) and anxiety (t1). Social interaction by internet was not a significant positive predictor of life satisfaction $(\mathrm{t} 2)$ and no variable related to internet use (t1) predicted life satisfaction ( $\mathrm{t} 2$ ).

The inclusion of individualism as a society-level variable and the interaction terms led to a slightly increased goodness of fit, according to $2 \log (\Delta=-2.24)$ and $\operatorname{AIC}(\Delta=-5.51)$, but not according to BIC $(\Delta-2 \log =39.87)$. Nevertheless, the individual-level results remained the same, and the country/society-level analyses did not reach conventional levels of significance.

After changing individualism to indulgence as a level-2 predictor, the results remained similar. The goodness of fit was better than in Model 2 according to $-2 \log (\Delta=-3.04)$ and $\operatorname{AIC}(\Delta=-3.91)$, but not according to BIC $(\Delta-2 \log =38.27)$. In addition, the same variables were significant, and neither the indulgence measure nor the interaction terms were significant.

The longitudinal test results did not support the first hypothesis of a negative effect of excessive internet use, nor support the displacement hypothesis. It was also inconsistent with the replacement hypothesis that posits a positive effect of social contact by internet on well-being.

The models for anxiety ( $\mathrm{t} 2$ ) are presented in Table 6 . The intraclass correlation was .06, and the inclusion of the independent variables in Model 2 


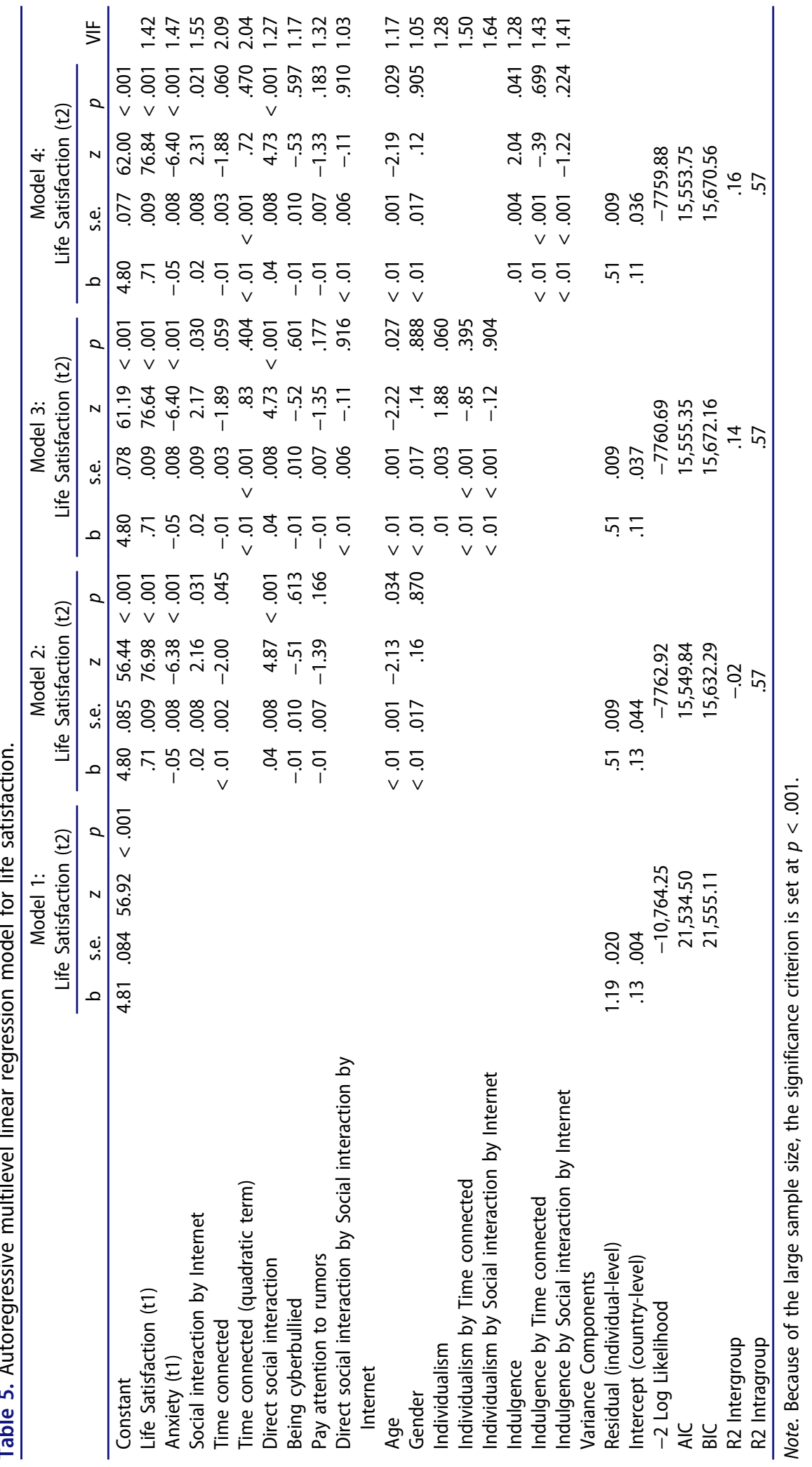




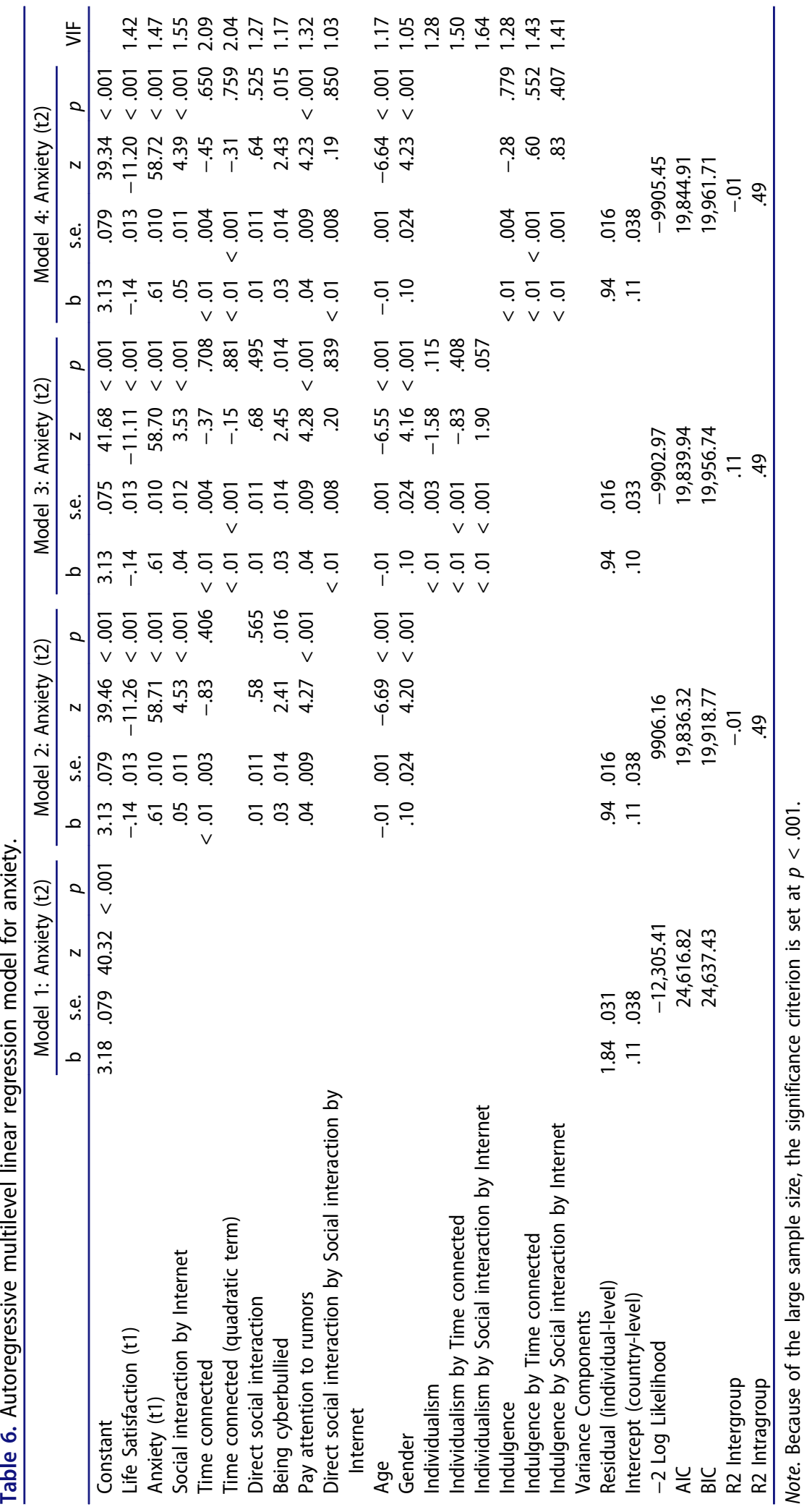


improved the goodness of fit according to three fit statistics $(\Delta-2 \log$ $=-2399.25, \Delta \mathrm{AIC}=-4780.50, \Delta \mathrm{BIC}=-4718.66)$, explaining $57 \%$ of individual-level variance. After controlling for baseline (anxiety t1), anxiety in the second wave was significant and positively predicted by social contact by internet ( $\mathrm{t} 1$ ), paying attention to rumors ( $\mathrm{t} 1$ ), and gender (i.e., females had higher scores), and negatively predicted by life satisfaction (t1) and age. In the third model, we included individualism as a country/society-level variable and the interaction terms, obtaining a slightly better goodness of fit according to $-2 \log (\Delta=-3.19)$, but not AIC $(\Delta=3.62)$ or BIC $(\Delta=37.97)$. Nevertheless, the pattern of results was the same as in the previous model, and none of the country/society-level variables and interaction terms were associated with anxiety. Finally, in the fourth model, when we included indulgence instead of individualism, the goodness of fit improved slightly compared to the second model $(-2 \log \Delta=-0.70$, AIC $\Delta=8.59$, BIC $\Delta=42.94)$, but the results still showed no influence of indulgence or its interaction terms.

Although higher social contact by internet (t1) increased anxiety ( $\mathrm{t} 2)$, it did not displace direct social interaction. In this sense, the regression models for anxiety refuted the replacement hypothesis: high internet use for social contact at time 1 was negatively related to affective well-being ( $\mathrm{t} 2)$. Specifically, internet use related to stressful content/process (i.e., following rumors) contributed to higher negative affect (i.e., anxiety).

It is important to remark that life satisfaction was predicted by (lower) anxiety and direct social contact and not by time connected online or any other variable related to internet use. By contrast, anxiety was predicted by life satisfaction and by following rumors on the internet. These results provide support for the idea of different correlates of internet use affecting cognitive or affective well-being.

Finally, three multiple regression models for life satisfaction and anxiety showed that country/society-level variables (e.g., individualism or indulgence) did not present a direct effect on outcomes nor moderate the association between individual-level variables.

\section{Discussion}

Longitudinal multiple linear regression models did not support the first hypothesis that frequency of internet use is detrimental for satisfaction with life and predicts anxiety. Correlational results provided initial support for the first hypothesis that stated that lower well-being is associated with greater use of the internet, congruent with meta-analyses indicating a small negative association between internet use and well-being (Çikrıkci, 2016; Huang, 2010). Amount of time online in time 1 correlated with low life satisfaction ( $\mathrm{t} 2, r=-.06)$, and anxiety $(\mathrm{t} 2, r=.13)$ at time 2 . These correlations are close to the main effect sizes found in previous meta- 
analyses. However, the most rigorous test of hypothesis 1, using longitudinal data and controlling for baseline well-being, did not support the hypothesis that frequency of internet use is the cause of lower subjective well-being. An alternative hypothesis that posits a curvilinear association profile was also unsupported.

Nor was the second hypothesis supported, that intensive internet use for communication displaces direct interaction and thus provokes negative outcomes. This second (displacement) hypothesis postulates that low subjective well-being is associated with high internet use and low direct social contact. Time online did not correlate with direct social interaction, and multivariate analysis did not support this hypothesis because time connected online was not relevant for anxiety symptoms or (lower) life satisfaction. Results suggested further that internet-mediated social contact is not generally negative (in concordance with Gosling \& Mason, 2015; Song et al., 2014). Nonetheless, social contact by internet was associated with higher anxiety symptoms at time 2 .

The third (replacement) hypothesis posits internet use as a form of compensatory coping, that plays a positive causal role for well-being, because it replaces already missing face-to-face contact. Dienlin et al. (2017) suggest that communication on social network sites reinforces face-to-face communication, leading to a slight increase in life satisfaction. Similar to this replacement idea, in correlational results, social contact by internet was associated with life satisfaction, but also to anxiety in our results. This suggests that such internet use has two aspects: one functional, and possibly related to replacement (the other is dysfunctional). However, multilevel regression did not support the replacement hypothesis, because time 1 social interaction by internet was not a significant positive predictor of life satisfaction or low anxiety at time 2 (in fact, it predicted higher anxiety at $\mathrm{t} 2$ ).

Longitudinal multiple regression results did not support the fourth hypothesis (augmentation) where internet use for communication complements existing social interaction and amplifies their effects in terms of positive and negative outcomes. This hypothesis posits that the interaction between direct social contact and internet use for social interaction at time 1 predicts well-being at time 2. In fact, the interaction term between direct and internet-based social contact was not significant.

Only direct social contact predicted life satisfaction at time 2 . Time connected online or variables related to internet were not relevant to life satisfaction longitudinally: that was explained only by direct social interaction in our data. This result is congruent with Trepte et al.'s (2015) work where only social support transacted in offline settings contributed to overall life satisfaction. Even if online social support is as effective as offline support for providing information, emotional and behavioral validation facets of social support may be better provided face to face. 
Our longitudinal study partially supported the fifth hypothesis of negative augmentation, that searching for rumors and exposure to bullying through the internet at time 1 predicts lower well-being at time 2. Multilevel regression analysis confirmed the hypothesis for the negative effect of following rumors on anxiety.

In relation to the sixth hypothesis, results demonstrated differential correlates between different uses of internet and different components of well-being. Multivariate results confirmed that direct social interaction predicted life satisfaction (Hervás \& López-Gómez, 2016; Lischetzke \& Eid, 2006; Lucas, Dyrenforth, \& Diener, 2008). Absence of predictive value for direct social contact on anxiety was expected because positive events and social support are less related to negative affect (Maybery et al., 2006). Moreover, following rumors at time 1 was a significant and positive predictor of anxiety at time 2 , congruent with the idea that internet use with stressful content can trigger high negative affect.

Finally, the societal-level or cultural hypothesis posited a positive effect of individualistic context on wellbeing, while hypotheses seven and eight posited that the negative association between frequency of internet use and well-being, as well as the positive association between social interaction by internet and well-being, are stronger in more individualistic and more indulgent nations. At odds with these hypotheses, contextual or societal-level factors did not show a direct effect or a cross-level interaction effect on life satisfaction and anxiety. Thus, sociocultural context did not moderate the association between individual variables. Furthermore, in contrast to other studies, individualism was not associated with life satisfaction (Basabe et al., 2002). Probably the low degrees of freedom (only 19 collective units) explain in part this null result, because the coefficient was positive as expected, but non-significant.

This study is not devoid of limitations. First, though significant, standardized betas for internet and social contact variables on well-being were low: the standardized beta was .05 for social interaction by internet and anxiety, and betas were of size .04 for both direct social contact and satisfaction with life and for following rumors on the internet and anxiety. These variables explained only around $1 \%$ of variance, which appears low according to Cohen's (1992) effect size guidelines. On the other hand, these guidelines were based principally on qualitative impressions-that is, they might be treated as a rule of thumb. Empirical synthesis of meta-analyses has shown that the median effect size was $r=.19$ in social psychology, $r=.16$ in organizational psychology and that $r=.11, .19$ and .29 correspond to the 25 th, 50th and 75th percentiles of a massive recent meta-analysis of personality differences (Cignac \& Szodorai, 2016). In other words, our effect sizes are typical effect sizes in psychology and other behavioral sciences, as well as similar to effect sizes found in meta-analyses on the association between internet use and wellbeing (between $r=-.039$ and $r=-.18$ ), that show 
a weighted mean correlation of $r=-.11$ (Çikrıkci, 2016; Huang, 2010; Song et al., 2014).

However, a more important limitation of this study is that it only measured twice dependent variables, not the independent ones. We are therefore unable to examine how changes in internet use accord with changes in wellbeing over time.

Another limitation is that cross-cultural invariance measurement was not attained. This means that our scales, while adequate for the purposes of this study, are imperfect measures. Better fit may not be possible in this case due to the use of multiple different languages and imprecision in translating difficult concepts across cultures.

Finally, we relied only on self-reports, and self-reported measures of internet use only correlate moderately with observations of actual use (Scharkow, 2016).

\section{Conclusion}

From the perspective of cross-sectional data, it can seem that excessive use of internet is problematic. A finer grained longitudinal analysis with proper controls did not support this idea, refuting the overall claim that excessive use of the internet produces decreases in mental health/subjective well-being. However, social contact by internet predicted anxiety longitudinally and when controlling other variables. This did confirm partially detrimental effects of internet use in terms of an increase in negative affect. We did not find evidence for the replacement hypothesis, as social interaction by the internet was not relevant for well-being when longitudinally analyzed. Positive augmented was neither supported after longitudinal controls were imposed. On the other hand, regarding the negative augmentation hypothesis, following rumors had a negative effect on affective well-being (i.e., anxiety) over time. Culture neither showed a direct influence nor moderated the associations. These results demonstrate the complexity of the relationships between internet usages and subjective well-being, and the importance of using longitudinal data when making causal claims.

Future research ought to examine other time periods. Our interval was six months between measurements, which is considered a middle term criterion for follow up. Some limited evidence suggests that only recent (within three months) social events have an influence on well-being (Suh, Diener, \& Fujita, 1996). Other studies suggest that social support and events have an influence on well-being in six months and even one year later (Nahum-Shani, Bamberger, \& Bacharach, 2011). While our results appeared to be robust, further longitudinal studies, future work using multiple measurement times, and different measurement intervals, would extend knowledge further. 


\section{Notes}

1. The scales, while not highly reliable in line with recommendations (e.g., Hu \& Bentler, 1999), are adequate for the purposes of the research, and better fit may not be possible due to the use of different languages used to formulate the question items.

2. We tested across nation's measurement invariance of the Life satisfaction and Anxiety scales. Based on multi-sample confirmatory factor analysis, configural equivalence (factor structure is the same across groups in a multi-group confirmatory factor analysis) and metric equivalence (factor loadings are similar across groups) using cultural region as multi-group reference were tested. However, goodness of fit indices was not satisfactory, and measurement invariance was not confirmed.

3. In any case, analyses carried out with these variables showed similar results in the Individualism-Collectivism effects reported here.

4. Effect sizes are considered according to Cohen's (1992) guidelines.

5. In the online Appendix are the models for each nation separately.

6. Factor analysis was carried out in waves one and two, and a one factor solution was rejected, excluding the presence of a common method bias. We used general means of all questions as a covariate to correct for responses bias and results were similar. These analyses are not included.

7. Given our limited sample size at level 2, we had to perform the analyses separately for this new measure. Complementary analyses using other dimensions, like power distance did not find significant effects.

\section{Disclosure statement}

No potential conflict of interest was reported by the authors.

\section{Funding}

This research was supported by Grant FA2386-15-1-0003 from the Asian Office of Aerospace Research and Development. It was also partially supported by the grant PSI2017-84145-P from the Spanish Ministry of Economy Industry and Competitiveness (MINECO) to the first author.Parts of the data (time 1 well-being and social media variables) were used, but analyzed in a completely different manner, in a manuscript currently under review.

\section{ORCID}

Dario Paez (1) http://orcid.org/0000-0002-8459-6037

Gisela Delfino (1) http://orcid.org/0000-0002-3732-184X

Salvador Vargas-Salfate (1) http://orcid.org/0000-0003-3306-4134

James H. Liu (D) http://orcid.org/0000-0003-0938-4752

Homero Gil De Zúñiga (1) http://orcid.org/0000-0002-4187-3604

Sammyh Khan (1) http://orcid.org/0000-0001-7048-9786

Maite Garaigordobil (D) http://orcid.org/0000-0002-8621-6245 


\section{References}

Anderson, E. L., Steen, E., \& Stavropoulo, V. (2017). Internet use and problematic internet use: A systematic review of longitudinal research trends in adolescence and emergent adulthood. International Journal of Adolescence and Youth, 22(4), 430-454. doi:10.1080/ 02673843.2016 .1227716

Antoci, A., Sabatini, F., \& Sodini, M. (2012). See you on Facebook! A framework for analyzing the role of computer-mediated interaction in the evolution of social capital. The Journal of Socio-Economics, 41(5), 541-547. doi:10.1016/j.socec.2012.04.024

Arthaud-Day, M. L., Rode, J. C., Mooney, C. H., \& Near, J. P. (2005). The subjective well-being construct: A test of its convergent, discriminant, and factorial validity. Social Indicators Research, 74(3), 445-476. doi:10.1007/s11205-004-8209-6

Basabe, N., Páez, D., Valencia, J., Gonzalez, J. L., Rimé, B., \& Diener, E. (2002). Cultural dimensions, socioeconomic development, climate, and emotional hedonic level. Cognition \& Emotion, 16(1), 103-125. doi:10.1080/02699930143000158

Basabe, N., \& Ros, M. (2005). Cultural dimensions and social behavior correlates: Individualism-collectivism and power distance. International Review of Social Psychology, 18(1), 189-225.

Caplan, S. E. (2005). A social skill account of problematic internet use. Journal of Communication, 55(4), 721-736. doi:10.1111/j.1460-2466.2005.tb03019.x

Castellacci, F., \& Tveito, V. (2018). Internet use and well-being: A survey and a theoretical framework. Research Policy, 47(1), 308-325. doi:10.1016/j.respol.2017.11.007

Cignac, G. E., \& Szodorai, E. T. (2016). Effect size guidelines for individual differences researchers. Personality and Individual Differences, 102, 74-78. doi:10.1016/j.paid.2016.06.069

Çikrıkci, O. (2016). The effect of internet use on well-being: Meta-analysis. Computers in Human Behavior, 65, 560-566. doi:10.1016/j.chb.2016.09.021

Cohen, J. (1992). A power primer. Psychological Bulletin, 112(1), 155-159. doi:10.1037/00332909.112.1.155

Davis, R. A. (2001). A cognitive-behavioral model of pathological Internet use. Computers in Human Behavior, 17(2), 187-195. doi:10.1016/S0747-5632(00)00041-8

Diener, E., \& Diener, M. (2009). Cross-cultural correlates of life satisfaction and self-esteem. In E. Diener (Ed.), Social indicators research series: Vol. 38. Culture and well-being: The collected works of Ed Diener (pp. 71-91). New York, NY, US: Springer Science + Business Media.

Dienlin, T., Masur, P. K., \& Trepte, S. (2017). Reinforcement or displacement? The reciprocity of FtF, IM, and SNS communication and their effects on loneliness and life satisfaction. Journal of Computer-Mediated Communication, 22(2), 71-87. doi:10.1111/ jcc4.12183

Dodge, R., Daly, A., Huyton, J., \& Sanders, L. (2012). The challenge of defining well-being. International Journal of Wellbeing, 2(3), 222-235. doi:10.5502/ijw.v2i3.4

Garaigordobil, M. (2011). Prevalencia y consecuencias del cyberbullying: Una revision [Prevalence and consequences of cyberbullying: A review]. International Journal of Psychology and Psychological Therapy, 11(2), 233-254.

Garcia Mazzieri, S. (2014, November). Bienestar eudaimónico y uso de redes sociales virtuales. [Eudaimonic well-being and use of virtual social networks]. Paper presented at the IV International Congress of Research of the Faculty of Psychology of the National University of La Plata, Argentina. Retrieved from http://sedici.unlp.edu.ar/ handle/10915/48408

Gelman, A., \& Hill, J. (2007). Data analysis using regression and multilevel/hierarchical models. New York, NY: Cambridge University Press. 
Gil de Zúñiga, H., Ardèvol-Abreu, A., Diehl, T., Patiño, M. G., \& Liu, J. H. (2019). Trust in institutional actors across 22 Countries. Examining political, science, and media trust around the world. Revista Latina De Comunicación Social, 74, 237-262. doi:10.4185/ RLCS-2019-1329-12en

Gil de Zúñiga, H., \& Liu, J. H. (2017). Second screening politics in the social media sphere: Advancing research on dual screen use in political communication with evidence from 20 countries. Journal of Broadcasting \& Electronic Media, 61(2), 193-219. doi:10.1080/ 08838151.2017.1309420

Gosling, S. D., \& Mason, W. (2015). Internet research in Psychology. Annual Review of Psychology, 66, 877-902. doi:10.1146/annurev-psych-010814-015321

Helliwell, J., Layard, R., \& Sachs, J. (2017). World Happiness Report 2017. New York, NY: Sustainable Development Solutions Network.

Hervás, G., \& López-Gómez, I. (2016). The power of extraverts: Testing positive and negative mood regulation. Anales De Psicología/Annals of Psychology, 32(3), 710-716. doi:10.6018/ analesps.32.3.261641

Hofstede, G. (2001). Culture's consequences (2nd ed.). London, UK: Sage.

Hofstede, G. (2011). Dimensionalizing cultures: The Hofstede model in context. Online Readings in Psychology and Culture, 2(1). doi:10.9707/2307-0919.1014

Hofstede, G. (2015). Dimensions data matrix. 6 dimensions for website (version 201512 08). Retrieved from https://geerthofstede.com/research-and-vsm/dimension-data-matrix/

$\mathrm{Hu}, \mathrm{L}$. T., \& Bentler, P. M. (1999). Cutoff criteria for fit indexes in covariance structure analysis: Conventional criteria versus new alternatives. Structural Equation Modeling: A Multidisciplinary Journal, 6(1), 1-55. doi:10.1080/10705519909540118

Huang, C. (2010). Internet use and psychological well-being: A meta-analysis. Cyberpsychology Behavior, and Social Networking, 13(3), 241-249. doi:10.1089/cyber.2009.0217

Huang, C. (2012). Internet use and psychological well-being. In Z. Yan (Ed.), Encyclopedia of research on cyber behavior (pp. 302-312). Hershey, PA: Information Science Reference.

Kim, J., LaRose, R., \& Peng, R. (2009). Loneliness as the cause and the effect of problematic internet use: The relationship between internet use and psychological well-being. CyberPsychology \& Behavior, 12(4), 451-455. doi:10.1089/cpb.2008.0327

Kowalski, R. M., Giumetti, G. W., Schoreder, A. N., \& Lattanner, M. R. (2014). Bullying in the digital age: A critical review and meta-analysis research amongst youth. Psychological Bulletin, 140(4), 1073-1137. doi:10.1037/a0035618

Kraut, R., Kiesler, S., Boneva, B., Cummings, J., Helgeson, V., \& Crawford, A. (2002). Internet paradox revisited. Journal of Social Issues, 58(1), 49-74. doi:10.1111/1540-4560.00248

Kraut, R., Patterson, M., Lundmark, V., Kiesler, S., Makopadhyay, T., \& Scherlis, W. (1998). Internet paradox. A social technology that reduces social involvement and psychological well-being? American Psychologist, 53(9), 1017-1031. doi:10.1037/0003-066X.53.9.1017

Lau, A. L. D., Cummins, R. A., \& Mcpherson, W. (2005). An investigation into the cross-cultural equivalence of the personal wellbeing index. Social Indicators Research, 72 (3), 403-430. doi:10.1007/s11205-004-0561-z

LeBreton, J. M., \& Senter, J. L. (2008). Answers to twenty questions about interrater reliability and interrater agreement. Organizational Research Methods, 11(4), 815-852. doi:10.1177/ 1094428106296642

Lee, S. (2009). Online communication and adolescent social ties: Who benefits more from internet use? Journal of Computer-Mediated Communication, 14(3), 509-531. doi:10.1111/ j.1083-6101.2009.01451.x

Lischetzke, T., \& Eid, M. (2006). Why extraverts are happier than introverts: The role of mood regulation. Journal of Personality, 74(4), 1127-1162. doi:10.1111/j.1467-6494.2006.00405.x 
Lucas, R. E., Dyrenforth, P. S., \& Diener, E. (2008). Four myths about subjective well-being. Social and Personality Psychology Compass, 2(5), 2001-2015. doi:10.1111/j.17519004.2008.00140.x

Maybery, D. J., Jones-Ellis, J., Neale, J., \& Arentz, A. (2006). The positive events scale. Social Indicators Research, 78(1), 61-83. doi:10.1007/s11205-005-4096-8

McKenna, K. Y., \& Bargh, J. A. (1999). Causes and consequences of social interaction on the internet: A conceptual framework. Media Psychology, 1(3), 249-269. doi:10.1207/ s1532785xmep0103_4

Muuse, L. D., Finkenauer, C., Kerkhorf, P., \& Billedo, C. J. (2014). A longitudinal study of the association between compulsive internet use and wellbeing. Computers in Human Behavior, 36, 21-28. doi:10.1016/j.chb.2014.03.035

Nahum-Shani, I., Bamberger, P. A., \& Bacharach, S. B. (2011). Social support and employee well-being: The conditioning effect of perceived patterns of supportive exchange. Journal of Health and Social Behavior, 52(1), 123-139. doi:10.1177/0022146510395024

Nezlek, J. B. (2008). An introduction to multilevel modeling for social and personality psychology. Social and Personality Psychology Compass, 2(2), 842-860. doi:10.1111/ j.1751-9004.2007.00059.x

Orban, A. (2018). The trouble knowing how much screen time is 'too much'. London, UK: BBC News. Retrieved from hppt://www.bbc.com/news/technology-42907037

Pantic, I. (2014). Online social networking and mental health. Cyberpsychology, Behavior, and Social Networking, 17(10), 652-657. doi:10.1089/cyber.2014.0070

Prizant-Passal, S., Shechner, T., \& Aderka, I. A. (2016). Social anxiety and internet use A meta-analysis: What do we know? What are we missing? Computers in Human Behavior, 62, 221-229. doi:10.1016/j.chb.2016.04.003

Przybylski, A. K., \& Weinstein, N. (2017). A large-scale test of the goldilocks hypothesis: Quantifying the relations between digital-screen use and the mental well-being of adolescents. Psychological Science, 28(2), 204-215. doi:10.1177/0956797616678438

Reinecke, L., Aufenanger, S., Beutel, M. E., Dreier, M., Quiring, O., Stark, B., ... Müller, K. W. (2017). Digital stress over the life span: The effects of communication load and internet multitasking on perceived stress and psychological health impairments in a German probability sample. Media Psychology, 20(1), 90-115. doi:10.1080/15213269.2015.1121832

Reis, H. T., Smith, S. M., Carmichael, C. L., Caprariello, P. A., Tsai, F. F., Rodrigues, A., \& Maniaci, M. R. (2010). Are you happy for me? How sharing positive events with others provides personal and interpersonal benefits. Journal of Personality and Social Psychology, 99(2), 311-329. doi:10.1037/a0018344

Russell, J. A., \& Carroll, J. M. (1999). On the bipolarity of positive and negative affect. Psychological Bulletin, 125(1), 3-30. doi:10.1037/0033-2909.125.1.3

Ryan, R. M., \& Deci, E. L. (2001). On happiness and human potentials: A review of research on hedonic and eudaimonic well-being. Annual Review of Psychology, 52(1), 141-166. doi:10.1146/annurev.psych.52.1.141

Scharkow, M. (2016). The accuracy of self-reported Internet use-A validation study using client log data. Communication Methods and Measures, 10(1), 13-27. doi:10.1080/ 19312458.2015.1118446

Shklovski, I., Kraut, R., \& Rainie, L. (2004). The Internet and social participation: Contrasting cross-sectional and longitudinal analyses. Journal of Computer-Mediated Communication, 10(1), JCMC1018. doi:10.1111/j.1083-6101.2004.tb00226.x

Song, H., Zmyslinski-Seelig, A., Kim, J., Drent, A., Victor, A., Omori, K., \& Allen, M. (2014). Does Facebook make you lonely?: A meta analysis. Computers in Human Behavior, 36, 446-452. doi:10.1016/j.chb.2014.04.011 
Spitzer, R., Kroenke, K., Williams, J., \& Löwe, B. (2006). A brief measure for assessing generalized anxiety disorder. The GAD-7. Archives of Internal Medicine, 166(10), 1092-1097. doi:10.1001/archinte.166.10.1092

Suh, E., Diener, E., \& Fujita, F. (1996). Events and subjective well-being: Only recent events matter. Journal of Personality and Social Psychology, 70(5), 1091-1102. doi:10.1037//00223514.70.5.1091

Trepte, S., Dienlin, T., \& Reinecke, L. (2015). Influence of social support received in online and offline contexts on satisfaction with social support and satisfaction with life: A longitudinal study. Media Psychology, 18(1), 74-105. doi:10.1080/15213269.2013.838904

Triandis, H. C. (2001). Individualism-collectivism and personality. Journal of Personality, 69 (6), 907-924. doi:10.1111/1467-6494.696169

Van Den Eijnden, R. J., Meerkerk, G. J., Vermulst, A. A., Spijkerman, R., \& Engels, R. C. (2008). Online communication, compulsive Internet use, and psychosocial well-being among adolescents: A longitudinal study. Developmental Psychology, 44(3), 655. doi:10.1037/0012-1649.44.3.655

\section{Appendix: Regression model for each nation}

Argentina

\begin{tabular}{|c|c|c|c|c|c|c|c|c|}
\hline & \multicolumn{4}{|c|}{$\begin{array}{l}\text { Model 1: Life satisfaction } \\
(\mathrm{t} 2)\end{array}$} & \multicolumn{4}{|c|}{ Model 2: Anxiety (t2) } \\
\hline & $\mathrm{b}$ & S.e. & $\mathrm{z}$ & $p$ & $\mathrm{~b}$ & S.e. & z & $p$ \\
\hline Constant & 5.21 & .059 & 87.86 & $<.001$ & 3.22 & .084 & 38.25 & $<.001$ \\
\hline Life satisfaction (t1) & .58 & .048 & 11.98 & $<.001$ & -.17 & .068 & -2.49 & .013 \\
\hline Anxiety $(\mathrm{t} 1)$ & -.11 & .033 & -3.27 & .001 & .61 & .046 & 13.20 & $<.001$ \\
\hline Social interaction by internet & .04 & .041 & 1.05 & .294 & .03 & .058 & .54 & .589 \\
\hline Time connected & $<.01$ & .010 & -.49 & .622 & .01 & .014 & .64 & .524 \\
\hline Direct social interaction & .09 & .040 & 2.28 & .023 & -.04 & .057 & -.79 & .431 \\
\hline Being cyberbullied or harassed online & .05 & .051 & .90 & .368 & -.08 & .072 & -1.12 & .264 \\
\hline Pay attention to rumors & $<.01$ & .029 & .01 & .993 & .05 & .042 & 1.19 & .235 \\
\hline $\begin{array}{l}\text { Direct social interaction by Social interaction by } \\
\text { internet }\end{array}$ & .03 & .028 & 1.11 & .267 & -.02 & .039 & -.49 & .628 \\
\hline Age & $<.01$ & .003 & -.70 & .485 & $<.01$ & .004 & .04 & .970 \\
\hline Gender & -.13 & .086 & -1.48 & .139 & -.01 & .121 & -.12 & .905 \\
\hline $\mathrm{F}$ & \multicolumn{4}{|c|}{$(10,274)=29.56, p<.001$} & \multicolumn{4}{|c|}{$(10,274)=30.62, p<.001$} \\
\hline R squared & \multicolumn{4}{|c|}{.519} & \multicolumn{4}{|c|}{.528} \\
\hline
\end{tabular}


Brazil

\begin{tabular}{|c|c|c|c|c|c|c|c|c|}
\hline & \multicolumn{4}{|c|}{$\begin{array}{l}\text { Model 1: Life satisfaction } \\
\text { (t2) }\end{array}$} & \multicolumn{4}{|c|}{ Model 2: Anxiety (t2) } \\
\hline & b & S.e. & z & $p$ & b & S.e. & $z$ & $p$ \\
\hline Constant & 4.96 & .082 & 60.47 & $<.001$ & 3.86 & .101 & 38.16 & $<.001$ \\
\hline Life satisfaction (t1) & .48 & .058 & 8.32 & $<.001$ & -.09 & .071 & -1.33 & 183 \\
\hline Anxiety (t1) & -.05 & .048 & -1.12 & .265 & .59 & .059 & 10.04 & $<.001$ \\
\hline Social interaction by internet & -.06 & .061 & -.97 & .331 & -.03 & .076 & -.35 & .726 \\
\hline Time connected & .01 & .011 & .65 & .516 & $<.01$ & .013 & -.27 & .787 \\
\hline Direct social interaction & .13 & .049 & 2.63 & .009 & .11 & .061 & 1.84 & .068 \\
\hline Being cyberbullied or harassed online & $<.01$ & .045 & .01 & .991 & -.01 & .055 & -.12 & .903 \\
\hline Pay attention to rumors & -.06 & .036 & -1.64 & .101 & .05 & .044 & 1.15 & .253 \\
\hline $\begin{array}{l}\text { Direct social interaction by Social interaction by } \\
\text { internet }\end{array}$ & .10 & .038 & 2.61 & .010 & -.06 & .047 & -1.35 & .179 \\
\hline Age & $<.01$ & .005 & .38 & .706 & -.01 & .006 & -2.06 & .041 \\
\hline Gender & -.01 & .113 & -.12 & .908 & .30 & .139 & 2.12 & .035 \\
\hline $\mathrm{F}$ & \multicolumn{4}{|c|}{$(10,254)=12.14, p<.001$} & \multicolumn{4}{|c|}{$(10,254)=19.87, p<.001$} \\
\hline R squared & \multicolumn{4}{|c|}{.323} & \multicolumn{4}{|c|}{.439} \\
\hline
\end{tabular}

China

\begin{tabular}{|c|c|c|c|c|c|c|c|c|}
\hline & \multicolumn{4}{|c|}{$\begin{array}{l}\text { Model 1: Life satisfaction } \\
\text { (t2) }\end{array}$} & \multicolumn{4}{|c|}{ Model 2: Anxiety (t2) } \\
\hline & b & S.e. & $\mathrm{z}$ & $p$ & b & S.e. & $\mathrm{z}$ & $p$ \\
\hline Constant & 4.89 & .046 & 107.34 & $<.001$ & 3.11 & .072 & 43.36 & $<.001$ \\
\hline Life satisfaction (t1) & .75 & .044 & 17.16 & $<.001$ & -.33 & .068 & -4.85 & $<.001$ \\
\hline Anxiety (t1) & -.07 & .037 & -1.75 & .081 & .40 & .059 & 6.83 & $<.001$ \\
\hline Social interaction by internet & .13 & .045 & 2.82 & .005 & -.03 & .071 & -.48 & .633 \\
\hline Time connected & $<.01$ & .009 & -.41 & .684 & .01 & .014 & .57 & .570 \\
\hline Direct social interaction & -.01 & .045 & -.29 & .771 & .03 & .071 & .47 & .642 \\
\hline Being cyberbullied or harassed online & -.03 & .032 & -.88 & .379 & .14 & .050 & 2.74 & .006 \\
\hline Pay attention to rumors & .01 & .028 & .26 & 792 & .04 & .044 & .86 & .393 \\
\hline $\begin{array}{l}\text { Direct social interaction by Social interaction by } \\
\text { internet }\end{array}$ & .03 & .037 & .83 & .406 & -.11 & .058 & -1.95 & .052 \\
\hline Age & $<.01$ & .003 & .08 & .935 & -.02 & .005 & -3.13 & .002 \\
\hline Gender & .02 & .075 & .30 & 765 & -.01 & .117 & -.13 & .899 \\
\hline $\mathrm{F}$ & \multicolumn{4}{|c|}{$(10,317)=57.81, p<.001$} & \multicolumn{4}{|c|}{$(10,317)=20.79, p<.001$} \\
\hline$R$ squared & \multicolumn{4}{|c|}{.646} & \multicolumn{4}{|c|}{.396} \\
\hline
\end{tabular}


Estonia

\begin{tabular}{|c|c|c|c|c|c|c|c|c|}
\hline & \multicolumn{4}{|c|}{$\begin{array}{l}\text { Model 1: Life satisfaction } \\
\text { (t2) }\end{array}$} & \multicolumn{4}{|c|}{ Model 2: Anxiety (t2) } \\
\hline & b & S.e. & $\mathrm{z}$ & $p$ & b & S.e. & $\mathrm{z}$ & $p$ \\
\hline Constant & 4.87 & .037 & 133.12 & $<.001$ & 2.67 & .050 & 53.86 & $<.001$ \\
\hline Life satisfaction (t1) & .73 & .031 & 23.21 & $<.001$ & -.05 & .043 & -1.10 & .272 \\
\hline Anxiety (t1) & -.06 & .025 & -2.27 & .023 & .62 & .034 & 17.90 & $<.001$ \\
\hline Social interaction by internet & -.02 & .025 & -.84 & .402 & .06 & .034 & 1.65 & .099 \\
\hline Time connected & -.01 & .008 & -.76 & .450 & -.03 & .011 & -2.37 & .018 \\
\hline Direct social interaction & .01 & .024 & .53 & .598 & $<.01$ & .032 & -.04 & .965 \\
\hline Being cyberbullied or harassed online & $<.01$ & .046 & .03 & .973 & .06 & .063 & .90 & .367 \\
\hline Pay attention to rumors & -.01 & .026 & -.28 & .782 & -.03 & .036 & -.76 & .445 \\
\hline $\begin{array}{l}\text { Direct social interaction by Social interaction } \\
\text { by internet }\end{array}$ & -.01 & .020 & -.67 & .501 & .01 & .027 & .22 & .825 \\
\hline Age & $<.01$ & .002 & -2.70 & .007 & $<.01$ & .002 & -1.99 & .047 \\
\hline Gender & .07 & .054 & 1.28 & .201 & .08 & .073 & 1.04 & .297 \\
\hline $\mathrm{F}$ & \multirow{2}{*}{\multicolumn{4}{|c|}{$(10,593)=91.44, p<.001$}} & \multicolumn{4}{|c|}{$(10,593)=55.21, p<.001$} \\
\hline$R$ squared & & & & & \multicolumn{4}{|c|}{.482} \\
\hline
\end{tabular}

Germany

\begin{tabular}{|c|c|c|c|c|c|c|c|c|}
\hline & \multicolumn{4}{|c|}{$\begin{array}{l}\text { Model 1: Life satisfaction } \\
\text { (t2) }\end{array}$} & \multicolumn{4}{|c|}{ Model 2: Anxiety (t2) } \\
\hline & b & S.e. & $z$ & $p$ & b & S.e. & $z$ & $p$ \\
\hline Constant & 5.14 & .047 & 108.27 & $<.001$ & 3.06 & .065 & 47.08 & $<.001$ \\
\hline Life satisfaction (t1) & 71 & .033 & 21.59 & $<.001$ & -.10 & .045 & -2.18 & .030 \\
\hline Anxiety (t1) & -.02 & .027 & -.86 & .389 & .65 & .037 & 17.56 & $<.001$ \\
\hline Social interaction by internet & -.02 & .025 & -.69 & .490 & .11 & .035 & 3.16 & .002 \\
\hline Time connected & -.02 & .008 & -2.26 & .025 & -.01 & .011 & -1.17 & .242 \\
\hline Direct social interaction & .04 & .032 & 1.30 & .195 & -.03 & .044 & -.73 & .464 \\
\hline Being cyberbullied or harassed online & -.06 & .036 & -1.53 & .128 & .04 & .050 & .73 & .463 \\
\hline Pay attention to rumors & .02 & .025 & .87 & .384 & .10 & .034 & 2.79 & .005 \\
\hline $\begin{array}{l}\text { Direct social interaction by Social interaction } \\
\text { by internet }\end{array}$ & -.01 & .019 & -.67 & .501 & .01 & .026 & .52 & .602 \\
\hline Age & $<.01$ & .002 & -.57 & .572 & $<.01$ & .003 & .55 & .582 \\
\hline Gender & -.05 & .065 & -.71 & .477 & .08 & .089 & .89 & .376 \\
\hline $\mathrm{F}$ & \multicolumn{4}{|c|}{$(10,500)=82.41, p<.001$} & \multicolumn{4}{|c|}{$(10,500)=66.23, p<.001$} \\
\hline$R$ squared & \multicolumn{4}{|c|}{622} & \multicolumn{4}{|c|}{.570} \\
\hline
\end{tabular}




\begin{tabular}{|c|c|c|c|c|c|c|c|c|}
\hline & \multicolumn{4}{|c|}{$\begin{array}{l}\text { Model 1: Life satisfaction } \\
\text { (t2) }\end{array}$} & \multicolumn{4}{|c|}{ Model 2: Anxiety (t2) } \\
\hline & b & S.e. & Z & $p$ & b & S.e. & z & $p$ \\
\hline Constant & 5.42 & .075 & 71.96 & $<.001$ & 3.22 & .107 & 30.19 & $<.001$ \\
\hline Life satisfaction (t1) & .67 & .052 & 13.01 & $<.001$ & -.17 & .073 & -2.37 & .019 \\
\hline Anxiety (t1) & -.12 & .045 & -2.70 & .007 & .55 & .063 & 8.78 & $<.001$ \\
\hline Social interaction by internet & .05 & .063 & .82 & .413 & .03 & .089 & .29 & .772 \\
\hline Time connected & .01 & .011 & 1.17 & .243 & $<.01$ & .016 & -.25 & .806 \\
\hline Direct social interaction & .04 & .056 & .69 & .488 & .05 & .079 & .70 & .486 \\
\hline Being cyberbullied or harassed online & .02 & .042 & .40 & .686 & .02 & .059 & .41 & .679 \\
\hline Pay attention to rumors & -.08 & .036 & -2.30 & .022 & .02 & .051 & .37 & .709 \\
\hline $\begin{array}{l}\text { Direct social interaction by Social interaction by } \\
\text { internet }\end{array}$ & -.03 & .044 & -.74 & .460 & .01 & .062 & .20 & .841 \\
\hline Age & $<.01$ & .006 & -.71 & .477 & -.01 & .008 & -1.82 & .070 \\
\hline Gender & -.25 & .102 & -2.48 & .014 & .22 & .145 & 1.54 & .124 \\
\hline $\mathrm{F}$ & \multicolumn{4}{|c|}{$(10,241)=32.60, p<.001$} & \multicolumn{4}{|c|}{$(10,241)=16.26, p<.001$} \\
\hline$R$ squared & \multicolumn{4}{|c|}{.575} & \multicolumn{4}{|c|}{.403} \\
\hline
\end{tabular}

Italy

\begin{tabular}{|c|c|c|c|c|c|c|c|c|}
\hline & \multicolumn{4}{|c|}{$\begin{array}{l}\text { Model 1: Life satisfaction } \\
\text { (t2) }\end{array}$} & \multicolumn{4}{|c|}{ Model 2: Anxiety (t2) } \\
\hline & b & S.e. & $\mathrm{z}$ & $p$ & b & S.e. & z & $p$ \\
\hline Constant & 4.82 & .052 & 93.20 & $<.001$ & 3.51 & .068 & 51.77 & $<.001$ \\
\hline Life satisfaction (t1) & .74 & .035 & 20.91 & $<.001$ & -.15 & .046 & -3.17 & .002 \\
\hline Anxiety (t1) & -.05 & .031 & -1.64 & .102 & .66 & .040 & 16.42 & $<.001$ \\
\hline Social interaction by internet & .04 & .032 & 1.24 & .216 & .11 & .042 & 2.57 & .011 \\
\hline Time connected & -.01 & .008 & -.98 & .327 & .01 & .010 & 1.21 & .226 \\
\hline Direct social interaction & .05 & .041 & 1.30 & .193 & -.02 & .053 & -.40 & .692 \\
\hline Being cyberbullied or harassed online & .02 & .037 & .48 & .629 & -.05 & .048 & -1.05 & .294 \\
\hline Pay attention to rumors & $<.01$ & .027 & -.14 & .892 & -.01 & .035 & -.38 & .708 \\
\hline $\begin{array}{l}\text { Direct social interaction by Social interaction by } \\
\text { internet }\end{array}$ & .01 & .022 & .34 & .732 & $<.01$ & .029 & -.08 & .934 \\
\hline Age & $<.01$ & .003 & -1.46 & .146 & $<.01$ & .004 & .71 & .476 \\
\hline Gender & -.02 & .068 & -.34 & .731 & .17 & .090 & 1.95 & 051 \\
\hline $\mathrm{F}$ & \multicolumn{4}{|c|}{$(10,476)=72.78, p<.001$} & \multicolumn{4}{|c|}{$(10,476)=45.33, p<.001$} \\
\hline R squared & \multicolumn{4}{|c|}{.605} & \multicolumn{4}{|c|}{.488} \\
\hline
\end{tabular}


Japan

\begin{tabular}{|c|c|c|c|c|c|c|c|c|}
\hline & \multicolumn{4}{|c|}{$\begin{array}{l}\text { Model 1: Life satisfaction } \\
\text { (t2) } \\
\end{array}$} & \multicolumn{4}{|c|}{ Model 2: Anxiety (t2) } \\
\hline & b & S.e. & z & $p$ & b & S.e. & z & $p$ \\
\hline Constant & 4.08 & .044 & 92.85 & $<.001$ & 2.69 & .056 & 47.98 & $<.001$ \\
\hline Life satisfaction (t1) & .79 & .034 & 23.03 & $<.001$ & -.20 & .044 & -4.59 & $<.001$ \\
\hline Anxiety (t1) & -.01 & .028 & -.51 & 613 & .65 & .036 & 17.99 & $<.001$ \\
\hline Social interaction by internet & .05 & .030 & 1.69 & 091 & .02 & .039 & .57 & .570 \\
\hline Time connected & $<.01$ & .008 & .02 & .985 & -.01 & .011 & -1.35 & .177 \\
\hline Direct social interaction & .01 & .026 & .51 & 611 & .02 & .034 & .55 & .581 \\
\hline Being cyberbullied or harassed online & -.02 & .047 & -.44 & .661 & $<.01$ & .060 & -.04 & .964 \\
\hline Pay attention to rumors & -.01 & .024 & -.59 & .553 & .02 & .031 & .63 & .530 \\
\hline $\begin{array}{l}\text { Direct social interaction by Social interaction by } \\
\text { internet }\end{array}$ & .01 & .017 & .50 & .620 & .02 & .022 & .77 & .439 \\
\hline Age & $<.01$ & .003 & 1.22 & .222 & -.01 & .004 & -2.28 & .023 \\
\hline Gender & .02 & .068 & .26 & .796 & .09 & .086 & 1.06 & .288 \\
\hline $\mathrm{F}$ & \multirow{2}{*}{\multicolumn{4}{|c|}{$(10,453)=90.47, p<.001$}} & \multicolumn{4}{|c|}{$(10,453)=68.10, p<.001$} \\
\hline R squared & & & & & \multicolumn{4}{|c|}{.601} \\
\hline
\end{tabular}

New Zealand

\begin{tabular}{|c|c|c|c|c|c|c|c|c|}
\hline & \multicolumn{4}{|c|}{$\begin{array}{l}\text { Model 1: Life satisfaction } \\
(\mathrm{t} 2)\end{array}$} & \multicolumn{4}{|c|}{ Model 2: Anxiety (t2) } \\
\hline & $\mathrm{b}$ & S.e. & z & $p$ & $\mathrm{~b}$ & S.e. & z & $p$ \\
\hline Constant & 5.11 & .044 & 115.29 & $<.001$ & 2.87 & .053 & 54.24 & $<.001$ \\
\hline Life satisfaction (t1) & .74 & .033 & 22.64 & $<.001$ & -.11 & .039 & -2.90 & .004 \\
\hline Anxiety (t1) & -.05 & .028 & -1.60 & .110 & .72 & .034 & 21.39 & $<.001$ \\
\hline Social interaction by internet & .02 & .028 & .62 & .534 & .03 & .033 & .76 & .446 \\
\hline Time connected & $<.01$ & .007 & -.31 & .754 & -.01 & .008 & -.83 & .405 \\
\hline Direct social interaction & .04 & .028 & 1.54 & .124 & .03 & .034 & .82 & .411 \\
\hline Being cyberbullied or harassed online & -.01 & .047 & -.24 & .809 & .12 & .056 & 2.08 & .038 \\
\hline Pay attention to rumors & -.02 & .029 & -.74 & .457 & -.01 & .035 & -.17 & .863 \\
\hline $\begin{array}{l}\text { Direct social interaction by Social interaction by } \\
\text { internet }\end{array}$ & -.03 & .020 & -1.33 & .185 & .03 & .023 & 1.14 & .257 \\
\hline Age & $<.01$ & .002 & -.32 & .746 & -.01 & .003 & -2.94 & .003 \\
\hline Gender & .01 & .060 & .17 & .864 & .02 & .072 & .27 & .788 \\
\hline $\mathrm{F}$ & \multicolumn{4}{|c|}{$(10,508)=95.36, p<.001$} & \multicolumn{4}{|c|}{$(10,508)=93.05, p<.001$} \\
\hline$R$ squared & \multicolumn{4}{|c|}{.652} & \multicolumn{4}{|c|}{647} \\
\hline
\end{tabular}




\begin{tabular}{|c|c|c|c|c|c|c|c|c|}
\hline & \multicolumn{4}{|c|}{$\begin{array}{l}\text { Model 1: Life satisfaction } \\
(\mathrm{t} 2)\end{array}$} & \multicolumn{4}{|c|}{ Model 2: Anxiety (t2) } \\
\hline & $\mathrm{b}$ & S.e. & z & $p$ & $\mathrm{~b}$ & S.e. & z & $p$ \\
\hline Constant & 5.14 & .150 & 34.32 & $<.001$ & 2.80 & .161 & 17.43 & $<.001$ \\
\hline Life satisfaction (t1) & .65 & .106 & 6.15 & $<.001$ & -.19 & .114 & -1.66 & .101 \\
\hline Anxiety $(\mathrm{t} 1)$ & -.10 & .092 & -1.03 & .303 & .47 & .099 & 4.74 & $<.001$ \\
\hline Social interaction by internet & -.15 & .111 & -1.37 & .172 & -.03 & .119 & -.22 & .829 \\
\hline Time connected & .01 & .017 & .65 & .519 & .01 & .019 & .56 & .573 \\
\hline Direct social interaction & .13 & .082 & 1.64 & .104 & -.14 & .088 & -1.60 & .114 \\
\hline Being cyberbullied or harassed online & .19 & .127 & 1.52 & .131 & .12 & .136 & .87 & .384 \\
\hline Pay attention to rumors & -.06 & .072 & -.77 & .442 & .08 & .077 & 1.05 & .296 \\
\hline $\begin{array}{l}\text { Direct social interaction by Social interaction by } \\
\text { internet }\end{array}$ & .01 & .082 & .16 & .872 & -.03 & .088 & -.29 & .772 \\
\hline Age & -.02 & .010 & -2.49 & .014 & $<.01$ & .010 & -.41 & 683 \\
\hline Gender & -.02 & .197 & -.09 & .929 & .23 & .211 & 1.09 & .278 \\
\hline $\mathrm{F}$ & \multicolumn{4}{|c|}{$(10,110)=7.39, p<.001$} & \multicolumn{4}{|c|}{$(10,110)=6.82, p<.001$} \\
\hline R squared & \multicolumn{4}{|c|}{.402} & \multicolumn{4}{|c|}{.383} \\
\hline
\end{tabular}

Poland

\begin{tabular}{|c|c|c|c|c|c|c|c|c|}
\hline & \multicolumn{4}{|c|}{$\begin{array}{l}\text { Model 1: Life satisfaction } \\
(\mathrm{t} 2)\end{array}$} & \multicolumn{4}{|c|}{ Model 2: Anxiety (t2) } \\
\hline & $\mathrm{b}$ & S.e. & $z$ & $p$ & $b$ & S.e. & z & $p$ \\
\hline Constant & 4.72 & .049 & 96.57 & $<.001$ & 3.14 & .075 & 41.94 & $<.001$ \\
\hline Life satisfaction (t1) & .68 & .036 & 18.70 & $<.001$ & -.13 & .055 & -2.41 & .017 \\
\hline Anxiety $(\mathrm{t} 1)$ & -.07 & .027 & -2.48 & .013 & .51 & .042 & 12.17 & $<.001$ \\
\hline Social interaction by internet & -.01 & .031 & -.21 & .831 & .08 & .047 & 1.78 & .075 \\
\hline Time connected & -.02 & .011 & -1.86 & .063 & $<.01$ & .017 & .11 & .909 \\
\hline Direct social interaction & .04 & .033 & 1.14 & .253 & -.05 & .050 & -.95 & .342 \\
\hline Being cyberbullied or harassed online & -.04 & .033 & -1.27 & .204 & .07 & .051 & 1.38 & .167 \\
\hline Pay attention to rumors & .04 & .024 & 1.72 & .085 & .05 & .037 & 1.44 & .152 \\
\hline $\begin{array}{l}\text { Direct social interaction by Social interaction by } \\
\text { internet }\end{array}$ & -.01 & .020 & -.52 & .601 & -.03 & .030 & -.95 & .341 \\
\hline Age & -.01 & .002 & -2.24 & .025 & -.01 & .004 & -2.27 & .024 \\
\hline Gender & -.01 & .067 & -.08 & .934 & .33 & .103 & 3.18 & .002 \\
\hline $\mathrm{F}$ & \multicolumn{8}{|c|}{$(10,476)=65.42, p<.001 \quad(10,476)=36.89, p<.001$} \\
\hline $\mathrm{R}$ squared & \multicolumn{4}{|c|}{.579} & \multicolumn{4}{|c|}{.437} \\
\hline
\end{tabular}


Russia

\begin{tabular}{|c|c|c|c|c|c|c|c|c|}
\hline & \multicolumn{4}{|c|}{$\begin{array}{l}\text { Model 1: Life satisfaction } \\
(\mathrm{t} 2)\end{array}$} & \multicolumn{4}{|c|}{ Model 2: Anxiety (t2) } \\
\hline & $b$ & S.e. & z & $p$ & $b$ & S.e. & z & $p$ \\
\hline Constant & 4.54 & .055 & 82.29 & $\begin{array}{l}< \\
.001\end{array}$ & 3.23 & .077 & 41.94 & $\begin{array}{l}< \\
.001\end{array}$ \\
\hline Life satisfaction (t1) & .76 & .040 & 19.05 & $\begin{array}{l}< \\
.001\end{array}$ & -.07 & .055 & -1.33 & .184 \\
\hline Anxiety (t1) & .02 & .032 & .64 & .520 & .56 & .045 & 12.29 & $\begin{array}{l}< \\
.001\end{array}$ \\
\hline Social interaction by internet & .01 & .033 & .16 & .872 & .03 & .046 & .66 & .508 \\
\hline Time connected & .01 & .009 & .59 & .558 & $<.01$ & .013 & -.11 & .915 \\
\hline Direct social interaction & .01 & .034 & .37 & .708 & .03 & .048 & .61 & .541 \\
\hline Being cyberbullied or harassed online & -.03 & .048 & -.69 & .488 & .01 & .067 & .18 & .857 \\
\hline Pay attention to rumors & -.02 & .027 & -.86 & .388 & .11 & .038 & 2.80 & .005 \\
\hline $\begin{array}{l}\text { Direct social interaction by Social interaction by } \\
\text { internet }\end{array}$ & .02 & .022 & .92 & .358 & -.03 & .030 & -.95 & .344 \\
\hline Age & -.01 & .003 & -2.18 & .030 & -.01 & .005 & -2.00 & .046 \\
\hline Gender & .05 & .077 & .69 & .492 & .04 & .108 & .35 & .726 \\
\hline $\mathrm{F}$ & (10, & 411) & $\begin{array}{l}=45.85 \\
001\end{array}$ & $p<$ & $(10,41$ & 11) $=3$ & $32.72, p$ & $<.001$ \\
\hline $\mathrm{R}$ squared & & & 527 & & .443 & & & \\
\hline
\end{tabular}

$\underline{\text { South Korea }}$

\begin{tabular}{|c|c|c|c|c|c|c|c|c|}
\hline & \multicolumn{4}{|c|}{$\begin{array}{l}\text { Model 1: Life satisfaction } \\
\text { (t2) }\end{array}$} & \multicolumn{4}{|c|}{ Model 2: Anxiety (t2) } \\
\hline & $b$ & S.e. & z & $p$ & $b$ & S.e. & z & $p$ \\
\hline Constant & 4.08 & .044 & 92.94 & $<.001$ & 2.95 & .070 & 42.07 & $<.001$ \\
\hline Life satisfaction (t1) & .73 & .034 & 21.41 & $<.001$ & -.14 & .054 & -2.52 & .012 \\
\hline Anxiety (t1) & -.03 & .028 & -1.06 & .291 & .58 & .044 & 13.02 & $<.001$ \\
\hline Social interaction by internet & .07 & .031 & 2.43 & .015 & -.07 & .049 & -1.37 & .172 \\
\hline Time connected & -.01 & .007 & -1.93 & .054 & $<.01$ & .011 & .02 & .987 \\
\hline Direct social interaction & .02 & .028 & .77 & .445 & -.07 & .045 & -1.53 & .126 \\
\hline Being cyberbullied or harassed online & .04 & .039 & 1.10 & .274 & .13 & .062 & 2.04 & .042 \\
\hline Pay attention to rumors & .05 & .023 & 2.12 & .034 & .08 & .037 & 2.11 & .035 \\
\hline $\begin{array}{l}\text { Direct social interaction by Social interaction by } \\
\text { internet }\end{array}$ & $<.01$ & .021 & .04 & .965 & -.01 & .033 & -.28 & .781 \\
\hline Age & $<.01$ & .003 & .34 & .731 & -.01 & .004 & -1.74 & .082 \\
\hline Gender & .03 & .061 & .49 & .624 & .23 & .098 & 2.36 & .018 \\
\hline $\mathrm{F}$ & \multicolumn{4}{|c|}{$(10,442)=86.01, p<.001$} & \multicolumn{4}{|c|}{$(10,442)=38.78, p<.001$} \\
\hline R squared & \multicolumn{4}{|c|}{.661} & \multicolumn{4}{|c|}{.467} \\
\hline
\end{tabular}


Spain

\begin{tabular}{|c|c|c|c|c|c|c|c|c|}
\hline & \multicolumn{4}{|c|}{$\begin{array}{l}\text { Model 1: Life satisfaction } \\
\text { (t2) }\end{array}$} & \multicolumn{4}{|c|}{ Model 2: Anxiety (t2) } \\
\hline & b & S.e. & $\mathrm{z}$ & $p$ & b & S.e. & z & $p$ \\
\hline Constant & 5.16 & .070 & 73.72 & $<.001$ & 3.10 & .100 & 31.15 & $<.001$ \\
\hline Life satisfaction (t1) & .73 & .049 & 15.01 & $<.001$ & -.10 & .069 & -1.51 & .131 \\
\hline Anxiety (t1) & -.05 & .037 & -1.24 & .215 & .65 & .053 & 12.25 & $<.001$ \\
\hline Social interaction by internet & .02 & .043 & 42 & .678 & .06 & .061 & 1.05 & .295 \\
\hline Time connected & .01 & .011 & .74 & .462 & -.01 & .016 & -.66 & .507 \\
\hline Direct social interaction & .09 & .052 & 1.70 & .090 & .12 & .074 & 1.57 & .118 \\
\hline Being cyberbullied or harassed online & -.04 & .064 & -.67 & .505 & .25 & .091 & 2.70 & .007 \\
\hline Pay attention to rumors & -.01 & .037 & -.18 & .855 & .06 & .052 & 1.10 & .273 \\
\hline $\begin{array}{l}\text { Direct social interaction by Social interaction by } \\
\text { internet }\end{array}$ & -.02 & .034 & -.64 & .524 & .10 & .049 & 2.13 & .035 \\
\hline Age & .01 & .004 & 1.37 & .174 & -.01 & .006 & -1.62 & .108 \\
\hline Gender & -.12 & .099 & -1.16 & .246 & .37 & .141 & 2.65 & .009 \\
\hline $\mathrm{F}$ & \multicolumn{4}{|c|}{$(10,226)=35.52, p<.001$} & \multicolumn{4}{|c|}{$(10,226)=29.54, p<.001$} \\
\hline$R$ squared & \multicolumn{4}{|c|}{.611} & \multicolumn{4}{|c|}{.567} \\
\hline
\end{tabular}

Taiwan

\begin{tabular}{|c|c|c|c|c|c|c|c|c|}
\hline & \multicolumn{4}{|c|}{$\begin{array}{l}\text { Model 1: Life satisfaction } \\
\text { (t2) }\end{array}$} & \multicolumn{4}{|c|}{ Model 2: Anxiety (t2) } \\
\hline & b & S.e. & z & $p$ & b & S.e. & $z$ & $p$ \\
\hline Constant & 4.38 & .072 & 60.91 & $<.001$ & 3.31 & .084 & 39.48 & $<.001$ \\
\hline Life satisfaction (t1) & .53 & .052 & 10.25 & $<.001$ & -.21 & .061 & -3.53 & $<.001$ \\
\hline Anxiety (t1) & -.01 & .048 & -.22 & .824 & .36 & .056 & 6.38 & $<.001$ \\
\hline Social interaction by internet & .03 & .055 & .55 & .583 & .05 & .064 & .83 & .406 \\
\hline Time connected & -.01 & .012 & -.54 & .586 & .02 & .014 & 1.06 & .291 \\
\hline Direct social interaction & .02 & .046 & .39 & .698 & .05 & .053 & .98 & .328 \\
\hline Being cyberbullied or harassed online & -.04 & .046 & -.89 & .376 & .02 & .054 & .34 & .730 \\
\hline Pay attention to rumors & -.04 & .037 & -1.09 & .277 & .10 & .043 & 2.38 & .018 \\
\hline $\begin{array}{l}\text { Direct social interaction by Social interaction by } \\
\text { internet }\end{array}$ & .01 & .038 & .34 & .734 & -.05 & .044 & -1.11 & .267 \\
\hline Age & $<.01$ & .004 & -.04 & .968 & $<.01$ & .005 & -.71 & .480 \\
\hline Gender & .10 & .094 & 1.04 & .300 & .06 & .110 & .53 & 600 \\
\hline $\mathrm{F}$ & \multicolumn{4}{|c|}{$(10,351)=17.85, p<.001$} & \multicolumn{4}{|c|}{$(10,351)=13.13, p<.001$} \\
\hline R squared & \multicolumn{4}{|c|}{.337} & \multicolumn{4}{|c|}{.272} \\
\hline
\end{tabular}


Turkey

\begin{tabular}{|c|c|c|c|c|c|c|c|c|}
\hline & \multicolumn{4}{|c|}{ Model 1: Life satisfaction (t2) } & \multicolumn{4}{|c|}{ Model 2: Anxiety (t2) } \\
\hline & b & $\begin{array}{l}\text { Std. } \\
\text { Err. }\end{array}$ & z & $p$ & b & $\begin{array}{l}\text { Std. } \\
\text { Err. }\end{array}$ & z & $p$ \\
\hline Constant & 4.54 & . 094 & 48.47 & $<.001$ & 3.71 & 111 & 33.50 & $<.001$ \\
\hline Life satisfaction (t1) & .62 & .059 & 10.62 & $<.001$ & -.09 & .069 & -1.24 & .216 \\
\hline Anxiety (t1) & -.09 & .054 & -1.73 & .084 & .50 & .064 & 7.81 & $<.001$ \\
\hline Social interaction by internet & -.01 & .068 & -.18 & .857 & .28 & .080 & 3.47 & .001 \\
\hline Time connected & -.01 & .013 & -.94 & .348 & $<.01$ & .015 & -.22 & .830 \\
\hline Direct social interaction & .02 & .068 & .23 & .820 & -.01 & .080 & -.15 & .877 \\
\hline Being cyberbullied or harassed online & .06 & .067 & .90 & .367 & .03 & .079 & .34 & .733 \\
\hline Pay attention to rumors & -.03 & .045 & -.71 & .476 & .06 & .053 & 1.06 & .291 \\
\hline $\begin{array}{l}\text { Direct social interaction by Social interaction } \\
\text { by internet }\end{array}$ & .01 & .053 & .20 & .843 & .01 & .063 & .16 & .873 \\
\hline Age & $<.01$ & .006 & .64 & .523 & -.01 & .007 & -1.79 & .075 \\
\hline Gender & -.15 & 127 & -1.15 & .253 & .01 & .150 & .07 & .947 \\
\hline $\mathrm{F}$ & \multicolumn{4}{|c|}{$(10,252)=19.42, p<.001$} & \multicolumn{4}{|c|}{$(10,252)=14.29, p<.001$} \\
\hline$R$ squared & \multicolumn{4}{|c|}{0.435} & \multicolumn{4}{|c|}{0.362} \\
\hline
\end{tabular}

Ukraine

\begin{tabular}{|c|c|c|c|c|c|c|c|c|}
\hline & \multicolumn{4}{|c|}{$\begin{array}{l}\text { Model 1: Life satisfaction } \\
\text { (t2) }\end{array}$} & \multicolumn{4}{|c|}{ Model 2: Anxiety (t2) } \\
\hline & b & S.e. & z & $p$ & b & S.e. & z & $p$ \\
\hline Constant & 4.05 & .212 & 19.13 & $<.001$ & 3.49 & .216 & 16.13 & $<.001$ \\
\hline Life satisfaction (t1) & .67 & .137 & 4.90 & $<.001$ & -.12 & .140 & -.86 & .395 \\
\hline Anxiety (t1) & -.04 & .109 & -.35 & .730 & .64 & .112 & 5.74 & $<.001$ \\
\hline Social interaction by internet & .04 & .121 & .33 & .743 & .19 & .123 & 1.54 & .128 \\
\hline Time connected & -.02 & .024 & -.82 & .416 & $<.01$ & .025 & -.05 & .957 \\
\hline Direct social interaction & .11 & .158 & .71 & .478 & -.03 & .162 & -.22 & .830 \\
\hline Being cyberbullied or harassed online & .10 & .182 & .52 & .602 & -.28 & .186 & -1.49 & .142 \\
\hline Pay attention to rumors & -.02 & .071 & -.33 & .742 & -.06 & .073 & -.86 & 391 \\
\hline $\begin{array}{l}\text { Direct social interaction by Social interaction by } \\
\text { internet }\end{array}$ & .09 & .155 & .57 & .569 & -.16 & .159 & -1.03 & .308 \\
\hline Age & $<.01$ & .010 & -.33 & .743 & -.02 & .011 & -2.09 & .040 \\
\hline Gender & .26 & .252 & 1.03 & .309 & -.20 & .258 & -.76 & .449 \\
\hline $\mathrm{F}$ & \multicolumn{4}{|c|}{$(10,69)=6.22, p<.001$} & \multicolumn{4}{|c|}{$(10,69)=6.77, p<.001$} \\
\hline R squared & \multicolumn{4}{|c|}{.474} & \multicolumn{4}{|c|}{.495} \\
\hline
\end{tabular}




\begin{tabular}{|c|c|c|c|c|c|c|c|c|}
\hline & \multicolumn{4}{|c|}{$\begin{array}{l}\text { Model 1: Life satisfaction } \\
\text { (t2) }\end{array}$} & \multicolumn{4}{|c|}{ Model 2: Anxiety (t2) } \\
\hline & b & S.e. & z & $p$ & b & S.e. & $z$ & $p$ \\
\hline Constant & 4.99 & .039 & 127.37 & $<.001$ & 3.02 & .055 & 55.16 & $<.001$ \\
\hline Life satisfaction (t1) & .81 & .029 & 27.65 & $<.001$ & -.12 & .041 & -2.82 & .005 \\
\hline Anxiety (t1) & -.04 & .022 & -1.77 & .078 & .74 & .031 & 23.68 & $<.001$ \\
\hline Social interaction by internet & .04 & .022 & 1.60 & .111 & .05 & .031 & 1.66 & .097 \\
\hline Time connected & $<.01$ & .006 & -.58 & .563 & -.01 & .009 & -1.04 & .300 \\
\hline Direct social interaction & .04 & .025 & 1.56 & .120 & .02 & .035 & .67 & .504 \\
\hline Being cyberbullied or harassed online & -.03 & .035 & -.99 & .324 & .06 & .049 & 1.15 & .251 \\
\hline Pay attention to rumors & $<.01$ & .026 & -.07 & .941 & -.01 & .036 & -.39 & .695 \\
\hline $\begin{array}{l}\text { Direct social interaction by Social } \\
\text { interaction by internet }\end{array}$ & -.03 & .016 & -1.84 & .066 & -.03 & .022 & -1.28 & .200 \\
\hline Age & $<.01$ & .002 & .86 & .392 & -.01 & .003 & -2.27 & .023 \\
\hline Gender & $<.01$ & .054 & -.05 & .961 & -.13 & .076 & -1.73 & .085 \\
\hline $\mathrm{F}$ & \multicolumn{4}{|c|}{$(10,563)=141.69, p<.001$} & \multicolumn{4}{|c|}{$(10,563)=125.23, p<.001$} \\
\hline R squared & \multicolumn{4}{|c|}{.716} & \multicolumn{4}{|c|}{.690} \\
\hline
\end{tabular}

United States

\begin{tabular}{|c|c|c|c|c|c|c|c|c|}
\hline & \multicolumn{4}{|c|}{$\begin{array}{l}\text { Model 1: Life satisfaction } \\
\text { (t2) }\end{array}$} & \multicolumn{4}{|c|}{ Model 2: Anxiety (t2) } \\
\hline & b & S.e. & $z$ & $p$ & $b$ & S.e. & $z$ & $p$ \\
\hline Constant & 5.19 & .046 & 112.48 & $<.001$ & 2.56 & .071 & 36.07 & $<.001$ \\
\hline Life satisfaction (t1) & .76 & .033 & 23.25 & $<.001$ & -.15 & .050 & -3.02 & .003 \\
\hline Anxiety (t1) & -.02 & .026 & -.87 & .383 & .65 & .041 & 16.07 & $<.001$ \\
\hline Social interaction by internet & .02 & .027 & .89 & .372 & .05 & .041 & 1.26 & .210 \\
\hline Time connected & $<.01$ & .007 & -.05 & .957 & $<.01$ & .010 & .28 & .777 \\
\hline Direct social interaction & .01 & .026 & .42 & .673 & .06 & .041 & 1.48 & .138 \\
\hline Being cyberbullied or harassed online & .04 & .042 & .91 & .365 & .06 & .065 & .96 & .340 \\
\hline Pay attention to rumors & -.01 & .029 & -.44 & .664 & -.05 & .045 & -1.09 & .278 \\
\hline $\begin{array}{l}\text { Direct social interaction by Social interaction } \\
\text { by internet }\end{array}$ & .01 & .018 & .36 & .716 & .06 & .027 & 2.16 & .031 \\
\hline Age & $<.01$ & .002 & 1.07 & .286 & -.01 & .003 & -2.43 & .016 \\
\hline Gender & $<.01$ & .061 & -.01 & .995 & .03 & .094 & .34 & .735 \\
\hline $\mathrm{F}$ & \multicolumn{4}{|c|}{$(10,397)=85.43, p<.001$} & \multicolumn{4}{|c|}{$(10,397)=54.50, p<.001$} \\
\hline R squared & \multicolumn{4}{|c|}{.683} & \multicolumn{4}{|c|}{.579} \\
\hline
\end{tabular}

